\title{
The structure of hematite $\left(\alpha-\mathrm{Fe}_{2} \mathrm{O}_{3}\right)(001)$ surfaces in aqueous media: Scanning tunneling microscopy and resonant tunneling calculations of coexisting $\mathrm{O}$ and $\mathrm{Fe}$ terminations
}

\author{
Carrick M. Eggleston, ${ }^{1, *}$ Andrew G. Stack, ${ }^{1}$ Kevin M. Rosso, ${ }^{2}$ Steven R. Higgins, ${ }^{1}$ Angela M. Bice, ${ }^{1}$ Steven W. Boese, ${ }^{1}$ \\ Richard D. Pribyl, ${ }^{1}$ and Jeremy J. Nichols ${ }^{1}$ \\ ${ }^{1}$ Department of Geology and Geophysics, University of Wyoming, Laramie, WY 82071-3006, USA \\ ${ }^{2}$ William R. Wiley Environmental Molecular Sciences Laboratory, Pacific Northwest National Laboratory, P.O. Box 999, MSIN K8-96, Richland, \\ WA 99352, USA
}

(Received January 22, 2002; accepted in revised form September 12, 2002)

\begin{abstract}
The iron oxide-water interface is of interest not only in geochemical and environmental processes, but also in fields ranging from corrosion to photocatalysis. The structure of $\alpha-\mathrm{Fe}_{2} \mathrm{O}_{3}(001)$ surfaces is not fully understood, and questions have arisen recently concerning different terminations of (001) terraces; a so-called Fe-termination is expected, but under some conditions an O-termination may also be possible. Ultra-high vacuum (UHV) scanning tunneling microscope (STM) studies report evidence for an O-termination in coexistence with an Fe-termination, but other studies find no evidence for an O-termination. Molecular mechanics studies suggest that an O-termination should be possible in an aqueous environment. An Otermination could result from dissolution; if $\mathrm{Fe}$ atoms were to dissolve from an Fe-termination, an $\mathrm{O}$ termination would presumably result (and vice-versa). We imaged hematite (001) surfaces in air and aqueous solution using STM. To aid interpretation of the images, we use a resonant tunneling model (RTM) parameterized using ab initio calculations.

Our STM and RTM results are consistent with mixed O- and Fe-terminated (001) surfaces. For acid-etched surfaces we find evidence for a periodic (with wavelength of $2.2 \pm 0.2 \mathrm{~nm}$ ) arrangement of nominal $\mathrm{O}$ - and Fe-terminated domains. Two different borders between domains should occur, one in which the Fe-termination is high relative to the O-termination, and the reverse. The different domain borders have significantly different heights, consistent with RTM calculations. This agreement allows us to conclude that the Fetermination is topographically high on most terraces. Surface domains are observed in aqueous solutions at the atomic scale, and appear to be very unreactive on tens-of-seconds time scales at pH 1. Copyright (C) 2003 Elsevier Science Ltd
\end{abstract}

\section{INTRODUCTION}

Iron oxides, and iron oxide surface chemistry, are of importance in fields including corrosion, lubrication (Jiang et al., 1997; Ramachandran et al., 1996), magnetic properties of materials, catalysis, and geochemical processes (Brown et al., 1999; Dzombak and Morel, 1990; Henrich and Cox, 1994). Fe is a ubiquitous reactant in the day-to-day chemical operation of the Earth's surface. $\mathrm{Fe}^{3+}$ is insoluble at midrange $\mathrm{pH}$ and thus often occurs as hydr(oxide) coatings on other minerals (Stumm and Morgan, 1996; Coston et al., 1995; Hendershot and Lavkulich, 1983; Scheidegger et al., 1993), thereby influencing natural water chemistry more than its bulk abundance might suggest. These influences often occur via the role of iron (hydr)oxides as sorbents for aqueous solutes (Dzomback and Morel, 1990; Kallay and Matijevic, 1985; Hug, 1997), and as an electron donor or acceptor in thermal (LaKind and Stone, 1989; Afonso et al., 1990; Suter et al., 1991), photoelectrochemical (Waite and Morel, 1984; Anderman and Kennedy, 1988; Faust et al., 1989; Sulzberger and Hug, 1994), and biologic (Lovley and Phillips, 1988; Nordstrom and Southam, 1997; Lovley, 1991) electron transfer.

Although we have a "stoichiometric" understanding of the $\mathrm{pH}$ and ligand dependence of iron oxide dissolution rates based

* Author to whom correspondence should be addressed (carrick@uwyo.edu). on relations between the concentration of adsorbed species and reaction rate in proton-promoted, ligand-promoted, and (photo)reductive dissolution (Stumm, 1992; Samson et al., 2000), we have not yet clearly coupled these observations to an understanding of the behavior of surface structures such as steps and terraces during dissolution (Burton et al., 1951). The role of iron oxides in natural systems depends fundamentally on surface atomic and electronic structure in the context of both dissolution-growth as well as interfacial electron transfer processes.

Recently, there has been interest in the detailed structure of $\alpha-\mathrm{Fe}_{2} \mathrm{O}_{3}$ (001) surfaces (Brown et al., 1999; Becker et al., 1996; Condon et al., 1994, 1995, 1998; Eggleston and Hochella, 1992; Henrich and Cox, 1994; Hochella et al., 1989; Wasserman et al., 1997), including fundamental questions concerning $\mathrm{Fe}$ - and O-terminations of (001) terraces (Chambers and Yi, 1999; Eggleston, 1999; Jones et al., 2000; Shaikhutdinov and Weiss, 1999; Thevuthasan et al., 1999; Wang et al., 1998). Figure 1a-d shows the basic idea of O- and Fe-terminations $\left(\mathrm{H}^{+}, \mathrm{H}_{2} \mathrm{O}\right.$, and $\mathrm{OH}^{-}$are omitted). In Figure 1e, the " $\mathrm{A}$ " type $\mathrm{Fe}$ sites are missing in the O-termination. Wang et al. (1998) proposed, on the basis of spin density functional theory (DFT) calculations and ultra-high vacuum (UHV) scanning tunneling microscopy (STM) imaging, that an O-terminated (001) surface forms when a hematite surface is exposed to high oxygen partial pressure. Eggleston (1999) proposed an O- or $\mathrm{OH}$-terminated surface in air on the basis of STM interpreted 
a)
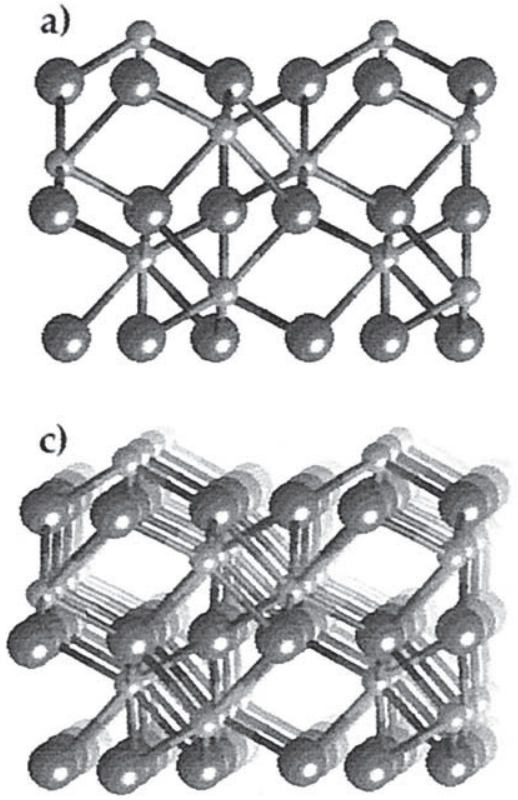

b)

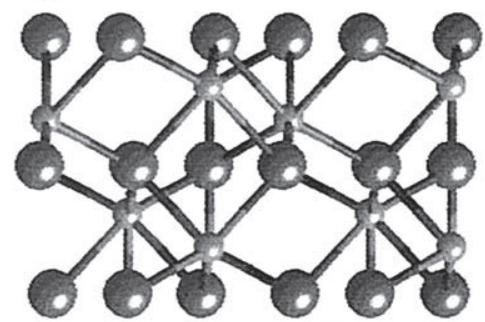

d)

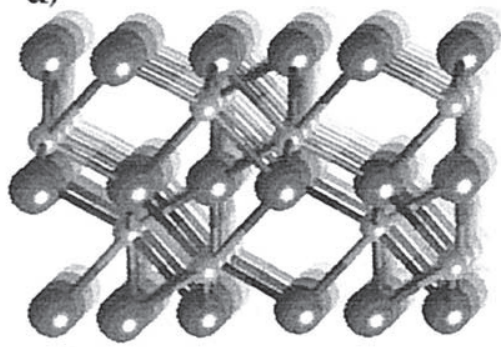

e)

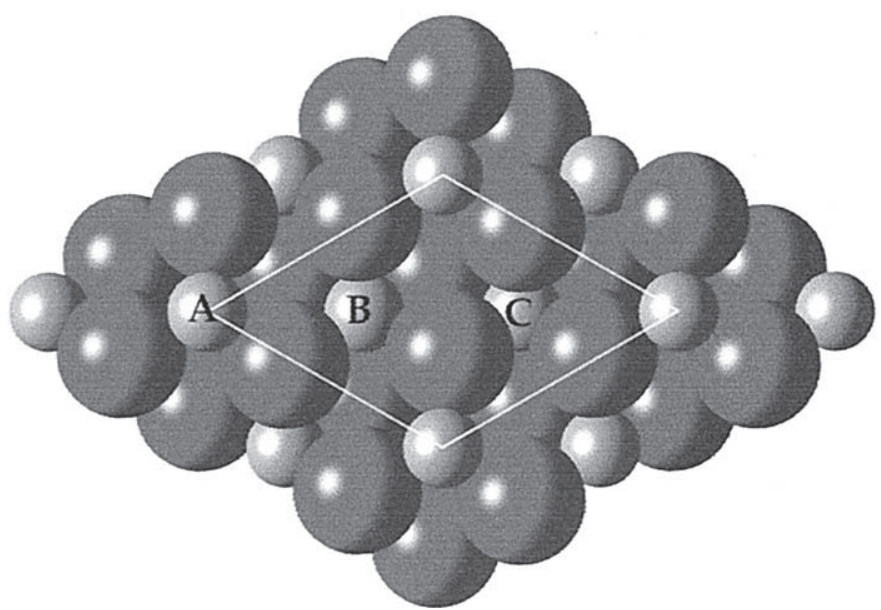

Fig. 1. Unrelaxed structures of the $\{001\}$ surface viewed along [100]. (a) Fe-terminated surface; in aqueous solution, the uppermost $\mathrm{Fe}$ ions will be coordinated by $\mathrm{H}_{2} \mathrm{O}$ or $\mathrm{OH}^{-}$. (b) O-terminated surface; in aqueous solution, we expect that the uppermost oxygen atoms occur as $\mathrm{OH}^{-}$and perhaps $\mathrm{H}_{2} \mathrm{O}$. (c and d) The same as (a) and (b), respectively, viewed slightly off of the [100] direction to show perspective on the Fe coordination and bonding. (e) In this view along [001], "A" sites are uppermost, and "B" and "C" sites are progressively lower. In the O-termination, "A" sites are missing.

with resonant tunneling theory. However, Thevuthasan et al. (1999) and Chambers and Yi (1999) found no spectroscopic evidence for an O-termination in vacuum. The purpose of this paper is to present STM evidence for the coexistence of Fe- and O-terminations on hematite (001) surfaces imaged in air and in solution.

Water and its dissociation products adsorb to the hematite surface (Henrich and Cox, 1994; Kurtz and Henrich, 1987; Liu et al., 1998). As used here, "O-termination" thus includes protonated terminal oxygens. Jones et al. (2000) show, on the basis of molecular mechanics calculations, that an O-terminated surface is possible under this definition.

When considering hematite surface structures that may exist in aqueous solution, we must consider the effects of dissolution as well as the possibility that the equilibrium termination may change as aqueous conditions, such as $\mathrm{pH}$, vary. For example, if A-type Fe sites (Fig. 1e) were to dissolve from an area of Fe termination, that area would then become an O-termination. In turn, O-terminations, likely with a differing reactivity with regard to dissolution, may give way to an Fe-termination as dissolution proceeds. In general, then, we might expect (001) hematite surfaces to contain both $\mathrm{Fe}$ - and O-terminations. The question we wish to answer here is: are in situ STM observations consistent with this hypothesis, and if so, how do the terminations distribute themselves on (001)? In addition, can we find any evidence for dissolution along domain boundaries in in-situ images at the atomic scale?

Below, we present STM images of hematite (001) surfaces in air and in aqueous solutions at neutral and low $\mathrm{pH}$. We concentrate on the domain structures (and height differences between them) pertinent to the question of coexisting $\mathrm{Fe}$ - and O-terminations. To aid interpretation of the images, we use a 
Table 1. Impurity concentrations in hematite from this study.

\begin{tabular}{lrlr}
\hline Impurity & Mass & Conductivity effect & $\begin{array}{r}\text { Concentration } \\
(\mathrm{mg} / \mathrm{kg})\end{array}$ \\
\hline $\mathrm{Mg}$ & 24 & Acceptor & 3.1 \\
$\mathrm{Ti}$ & 47 & Donor & 13.4 \\
$\mathrm{~V}$ & 51 & None & 144.5 \\
$\mathrm{Cr}$ & 52 & Trap & 1.4 \\
$\mathrm{Mn}$ & 55 & Trap & 2.4 \\
$\mathrm{Ni}$ & 61 & Acceptor & 0.6 \\
$\mathrm{Cu}$ & 63 & Acceptor & 0.1 \\
$\mathrm{Zr}$ & 90 & Donor & 1.2 \\
$\mathrm{Nb}$ & 93 & Double donor & 0.3 \\
$\mathrm{Sn}$ & 118 & Donor & 54.7 \\
$\mathrm{Ta}$ & 181 & Double donor & trace \\
\hline
\end{tabular}

resonant tunneling model (RTM) parameterized with ab initio calculations. The RTM allows us to include the effects of solvent water on electron transfer kinetics pertinent both to STM as well as other interfacial electron transfer reactions. The results are relevant both to the atomic surface structure of hematite in air and aqueous solution and to the relation of this structure to interfacial electron transfer processes.

\section{EXPERIMENTAL}

\subsection{Hematite}

Natural hematite from Tarascon sur Ariège, France, was initially imaged with atomic force microscopy (AFM) as received. A subset of samples were boiled in $1 \mathrm{~mol} / \mathrm{L}$ nitric acid for $1 \mathrm{~h}$, and then rinsed in distilled, deionized $(>18 \mathrm{~mol} / \mathrm{L} \Omega$ ) water (DDI water) before imaging. Because we were not initially looking for the regular surface modulations that were later observed, we did not control the time of subsequent storage at room temperature before STM imaging; however, this storage time was never more than a few weeks.

Donor impurities usually make natural hematite an $n$-type semiconductor at $25^{\circ} \mathrm{C}$. The Hall effect is not useful for the determination of conductivity type in hematite, but Shuey (1975) showed that hematite follows the relation $\mathrm{C}_{\mathrm{imp}}=10^{-2} / \mathrm{R}_{25^{\circ} \mathrm{C}}$ where $\mathrm{C}_{i m p}$ is the concentration of donor impurities in atom $\%$ and $\mathrm{R}_{25^{\circ} \mathrm{C}}$ is resistivity in $\Omega$-m. Our hematites had $\mathrm{R}_{25^{\circ} \mathrm{C}}=0.24 \Omega$-m to $10 \Omega$-m using a four-point probe on the basal plane, giving estimated impurity concentrations (donors minus acceptors) of $\sim 1 \times 10^{-3}$ to $4 \times 10^{-2}$ atom $\%$. We analyzed the hematite for common donors, acceptors, and electron traps using a Perkin-Elmer Elan 6000 inductively coupled plasma mass spectrometer (ICP-MS) with laser ablation (calibrated to NIST 610 glass). The total donor minus acceptor concentration is $2.0 \times 10^{-3}$ atom\% (Table 1 ),

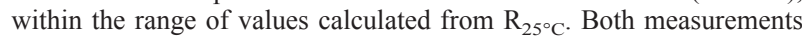
are semiquantitative, but confirm that our hematite is $n$-type (donors are significantly more concentrated than acceptors) and show that the main donor impurities are Sn and Ti. V impurity does not affect conduction (Shuey, 1975).

\subsection{Scanning Tunneling and Atomic Force Microscopy}

A Digital Instruments (DI) Nanoscope IIIa controller was used to run a DI STM (320 nm scanner), a Molecular Imaging (MI) STM (1.4 $\mu \mathrm{m}$ scanner) with a fluid cell, and a DI AFM operating in contact mode using uncoated silicon cantilevers with a nominal force constant of 0.02 to $0.8 \mathrm{~N} / \mathrm{m}$. STM tips (MI) were coated with Apiezon wax and tested for leakage currents of less than $70 \mathrm{pA}$. Imaging conditions are given in the figure captions.

In STM imaging, multiple tip artifacts are the rule rather than the exception (Eggleston, 1999), and criteria for selecting relatively artifact-free images for interpretation are necessary. We exclude images that show only a single broad, ill-defined bump every unit cell because they almost certainly result from the sum of signals coming from multiple subtips. For example, we often see poor resolution through part of a scan and then, because of a change in tip characteristics, good resolution of the same structure through the rest of the scan. A second selection was made on the basis of the nature of imaged defects; if there is a pattern or motif that repeats for every defect, a multiple tip is indicated. Therefore, we present here only high-resolution images that do not show these artifactual characteristics unless there is an important feature of the image that is independent of the artifact. There remains the possibility of variation in image detail, however, because of variations in the properties of the tip over an imaging session.

\subsection{Aqueous Solutions}

DDI water was used for circumneutral $\mathrm{pH}$ imaging and sample pretreatment; $\mathrm{pH} 1 \mathrm{HCl}$ solutions and concentrated nitric acid were, or were made from, Fisher TraceMetal Grade stock solutions.

\section{RESONANT TUNNELING MODEL}

\subsection{Background}

When an $\mathrm{Fe}^{3+}$ ion in aqueous solution is reduced to $\mathrm{Fe}^{2+}$, significant changes in $\mathrm{Fe}-\mathrm{O}$ bond lengths and surrounding solvent structure must occur. Such solvent reorganization is a measure of the activation energy for the electron transfer reaction (Marcus, 1956, 1965; Marcus and Sutin, 1985). Because reorganization energies for electron transfer to and from hydrated $\mathrm{Fe}^{3+}$ or $\mathrm{Fe}^{2+}$ are relatively large (equal to $\sim 100 \mathrm{kT}$ or $2.6 \mathrm{eV}$; Graetzel, 1989), it is important to include solvent reorganization in considering the energetics and kinetics of electron transfer to and from hematite in air or water. Schmickler and Widrig (1992) proposed a method for calculating current through a redox-active monolayer adsorbed to a metal substrate. The idea was applied theoretically to STM (Schmickler, 1993) and to experimental STM data (Tao, 1996; Schmickler and Tao, 1997) for electron transfer from graphite to an STM tip through Fe protoporphyrins. An initial adaptation of the RTM to hematite is discussed in Eggleston (1999). Below, we discuss further adaptations of the RTM to hematite; parameterization of the RTM with ab initio calculations is described in the Appendix.

\subsubsection{Adaptation of the RTM to Hematite}

In the RTM, the electronic states of the substrate and the STM tip resonate with a redox center located between the two (Fig. 2). If the Fermi level $\left(\mathrm{E}_{\mathrm{F}}\right)$ of the substrate and tip are far from the reduction potential of the redox center, little current will flow through the redox center. If the $\mathrm{E}_{\mathrm{F}}$ of the substrate is brought to a potential near the reduction potential of the redox center, the current through the redox center becomes comparable to that through the substrate and, because the redox centers are physically higher than the substrate, the redox centers thus appear highest in an STM image. Here, we are using the RTM to calculate the effects of varying bias voltage, not of varying electrode potential at fixed bias (Tao, 1996; Schmickler and Tao, 1997). By raising the bias voltage at fixed tip potential, for example, we bring the substrate into resonance with the redox centers, but do not vary the $\mathrm{E}_{\mathrm{F}}$ of the tip.

Our treatment only considers tunneling to and from iron atoms, in agreement with previous findings (Eggleston, 1999; Tarrach et al., 1993). The A, B, and C sites (Fig. 1e) are the resonators, and the underlying bulk hematite is the substrate. Electron transfer (ET) occurs in two steps; for current from 


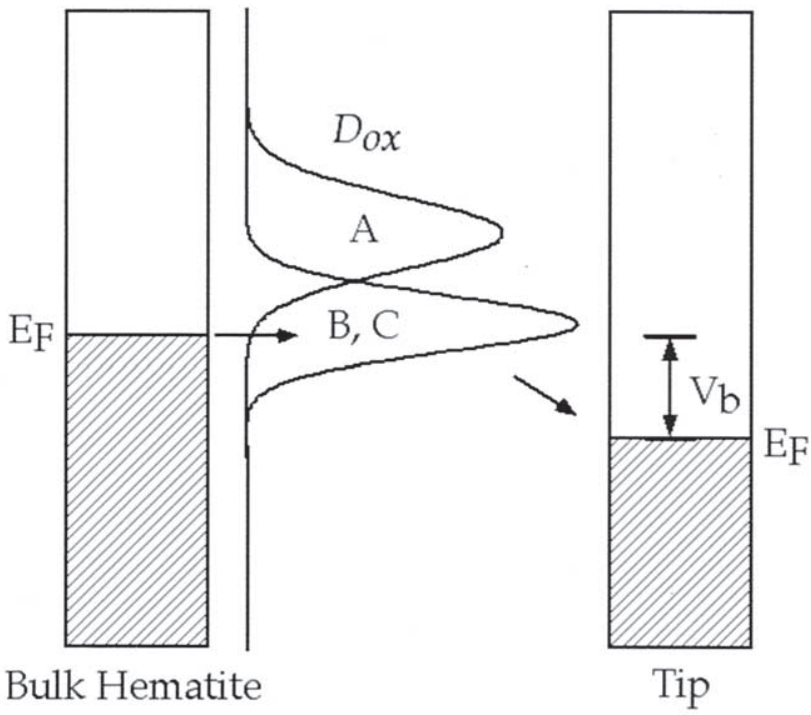

Fig. 2. Illustration of the resonant tunneling configuration for a negative bias voltage (sample biased negatively relative to the tip). For the Fe-termination "A" sites have an energetically different density of states than do "B" and "C" sites (see Fig. 1e). The arrows indicate electron transfer steps from substrate to surface redox centers, and then from the redox centers to the tip. $E_{F}$ is the Fermi level, $V_{b}$ is the bias voltage, and $D_{O x}$ is defined in Eqns. 1 and 2.

substrate to tip (Fig. 2), ET occurs first from the substrate to the redox-center $(s r)$, and then from the redox-center to the tip $(r t)$. We assume that the density of states (DOS) of substrate and tip are independent of bias voltage, and that the tunneling probability for each of the two electron transfer steps is not a function of bias voltage. The tunneling current, $j$ is then:

$$
j \propto-e_{0} \frac{\pi}{\hbar} \exp \left(-\beta_{r t} d_{r t}\right) \exp \left(-\beta_{s l} d_{s r}\right) \int_{0}^{e V_{b}} D_{o x}(\varepsilon) d \varepsilon
$$

where $\beta$ is the tunneling decay constant for the couple indicated by the subscript, $d$ is the distance between the designated couple (the nearest neighbor $\mathrm{Fe}$ atoms are considered the substrate, which determines the $d_{s r}$ distances), $\varepsilon$ is the electron energy, and $V_{b}$ is the STM sample bias voltage relative to the tip. The current thus becomes proportional to the density of unoccupied states on the resonator, also called the density of oxidized states $D_{o x}(\varepsilon)$, which is approximated by a gaussian:

$$
D_{o x}(\varepsilon)=\sqrt{\frac{\pi}{k T \lambda}} \exp \left[\frac{-\left(\varepsilon-\varepsilon_{r}\right)^{2}}{4 \lambda k T}\right]
$$

where $\lambda$ is the Marcus reorganization energy (Marcus, 1956), and $\varepsilon_{\mathrm{r}}$ is the reduction potential of the redox-center. The $\lambda$ term allows us to incorporate the effect of a solvent on the surface states. A larger $\lambda$, as might be expected for an A type iron atom coordinated by one or more waters, will give a broader but less intense $D_{o x}(\varepsilon) . \lambda$ can be separated into inner-sphere $\left(\lambda_{\text {is }}\right)$ and outer-sphere $\left(\lambda_{\mathrm{os}}\right)$ components (Marcus, 1965). We adopt this approach and calculate the terms separately (see the Appendix).

We treat the surface $\mathrm{Fe}$ atoms as isolated redox centers with no electronic coupling to the substrate at the energy of interest. Such coupling results in broadening of the apparent $D_{o x}(\varepsilon)$, due to interactions with the band structure of the solid substrate, and can be incorporated into the RTM (Schmickler and Widrig, 1992). To the extent that such coupling occurs, calculated resonance peak widths will be underestimated. We justify our approach by noting that $\lambda$ is relatively high [and $D_{o x}(\varepsilon)$ therefore broad] in our case, and that hematite can be described using a localized electron model (Goodenough, 1972) in which orbital coupling within the solid is not as good as in a metal. Confirmation of the degree of coupling for hematite must await the measurement of resonance peak widths for hematite surface sites and their comparison to calculated $\lambda$ values (Table 2).

Our RTM only considers ET through surface redox centers, not direct ET from the substrate to the tip. The calculated images are therefore most relevant when the bias voltage places the potential of the hematite near a resonance with surface Fe atoms. In practice, this means bias voltages that are not too large (roughly a $-500 \mathrm{mV}$ to $+500 \mathrm{mV}$ range). We have not always limited our STM imaging to this range, however.

The local electric fields imposed by the STM tip at larger bias are likely to distort the local DOS and, through alteration of the local work functions of tip and sample, the transmission probability (Hiesgen et al., 2001). In addition, there should be no shift in the $E_{F}$ of the redox center when the Fermi level of

\begin{tabular}{|c|c|c|c|c|c|c|c|}
\hline Site & $\begin{array}{c}\beta_{\mathrm{sr}} \\
\left(\AA^{-1}\right)\end{array}$ & $\begin{array}{c}\beta_{\mathrm{rt}} \\
\left(\AA^{-1}\right)\end{array}$ & $\begin{array}{l}d_{\mathrm{sr}} \\
(\AA)\end{array}$ & $\begin{array}{c}\lambda_{\text {is }} \\
(\mathrm{eV})\end{array}$ & $\begin{array}{c}\lambda_{\mathrm{os}} \\
(\mathrm{eV})\end{array}$ & $\begin{array}{c}\varepsilon_{\mathrm{r}} \\
(\mathrm{eV})\end{array}$ & $\mathrm{NN}$ \\
\hline \multicolumn{8}{|l|}{ Spin allowed } \\
\hline \multicolumn{8}{|l|}{ Fe-termination } \\
\hline A & 1.2 & 1.2 & 3.290 & 0.474 & 1.686 & 0.40 & 3 \\
\hline $\mathrm{B}, \mathrm{C}$ & $1.0 / 1.2$ & $1.0 / 1.2$ & 2.959 & 0.274 & 0.126 & 0.00 & 3 \\
\hline \multicolumn{8}{|l|}{ O-termination } \\
\hline B & $1.0 / 1.2$ & $1.0 / 1.2$ & 2.948 & 0.287 & 0.111 & 0.02 & 3 \\
\hline $\mathrm{C}$ & $1.0 / 1.2$ & $1.0 / 1.2$ & 2.948 & 0.274 & 0.111 & 0.02 & 3 \\
\hline A (3rd Fe layer) & $1.0 / 1.2$ & $1.0 / 1.2$ & 2.995 & 0.274 & 0.111 & 0.00 & 3 \\
\hline \multicolumn{8}{|l|}{ Spin forbidden } \\
\hline \multicolumn{8}{|l|}{ Fe-termination } \\
\hline A & 1.2 & 1.2 & 3.550 & 0.474 & 1.686 & 0.40 & 1 \\
\hline
\end{tabular}

Table 2. Parameters used in the RTM.

Columns containing 1.0/1.2 indicate that we made calculations for both cases (see appendix). Other symbols are defined in the text, except "NN" which indicates the number of equivalent "nearest neigbors." 


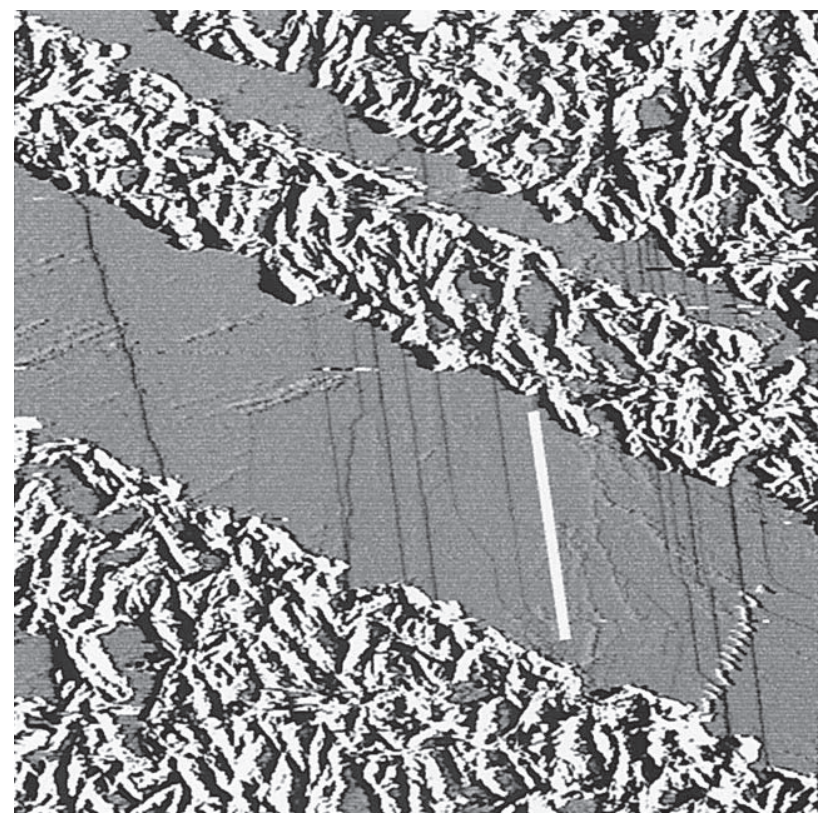

Fig. 3. A $5 \times 5 \mu \mathrm{m}$ contact AFM image in deflection mode (the image appears illuminated from the right) of the as-received hematite (001) surface. Z range is $1.7 \mathrm{~nm}$ deflection. Heavy white line shows the preferred step orientation along $\langle 100\rangle$. Some steps do not macroscopically follow the $\langle 100\rangle$ orientation, but are partially composed of segments that do so. The image also shows abundant evidence of particles being "dragged" across the surface by the AFM tip during imaging.

the substrate is varied. This amounts to saying that the electronic states of the redox center do not "fill up" when we raise the potential of the hematite bulk. For hematite, such "filling" of the states of the redox center would result in the formation of $\mathrm{Fe}^{2+}$ at the surface, which would in turn likely result in reductive dissolution in water. Our images taken in situ are remarkably stable; we do not observe extensive, rapid dissolution attributable to reductive dissolution.

\section{RESULTS AND DISCUSSION}

\subsection{AFM of As-received Surfaces}

On the natural hematite (001) surfaces, before any treatment, areas of "clean" hematite were found to be interspersed with crystallographically bounded regions covered by apparent goethite crystallites (Fig. 3) oriented preferentially along three axes separated by angles of $60^{\circ}$. Similar coverage of hematite (001) with crystallites has been observed previously (Junta-Rosso and Hochella, 1996) on some hematite parting surfaces. The orientation of the crystallites in Figure 3 is $\sim 30^{\circ}$ different from the preferred step orientations. According to Barrón et al. (1997), goethite grown epitaxially on hematite has its [001] direction oriented along the $\langle 210\rangle$ directions in hematite. This relationship preserves the continuity of the oxygen sublattice between the two minerals. Within this relationship, the preferred step orientation is $\langle 100\rangle$. It should be noted, however, that most of the crystallites could be removed by ultrasound.

\subsection{STM in Air of Nitric Acid Etched and Sonicated Surfaces}

In vacuum, Wang et al. (1998) and Shaikhutdinov and Weiss (1999) observed 0.1 to $0.15 \mathrm{~nm}$ height differences (i.e., substantially less than the $0.23 \mathrm{~nm}$ octahedral layer thickness), as well as corrugation differences, between surface domains. These observations, supported with spin density functional theory calculations, were taken as evidence for the existence of two different surface structures attributed to Fe- and O-terminations. Our results (from air and aqueous solution) may not agree with those from UHV because, aside from differences in imaging conditions, the electron transfer characteristics of surface sites should differ substantially between the UHV and aqueous situations because of electronic structure differences and solvent reorganization effects (section 3.1). However, if these structures coexist as domains on terraces, we should find two different borders between terminations, one in which the Fe-termination forms the topographically high side of the border, and the reverse. The height differences on both borders should add up to $0.23 \mathrm{~nm}$, but there is no a priori constraint on what each height difference should be individually.

Steps and terraces were observed on the cleaned $\{001\}$ surface; maximum terrace width was over $300 \mathrm{~nm}$ on some, but not all, parts of the surface (Fig. 4). A series of step height measurements were made from a single point on the high side of a step in Figure $4 \mathrm{~b}$ to a variety of locations on the low side of the step. This revealed a bimodal distribution of step heights, one averaging $0.17 \pm 0.03 \mathrm{~nm}$ and another averaging $0.23 \pm$ $0.02 \mathrm{~nm}$. Height variation within a single terrace (based on a series of individual measurements) was $0.04 \pm 0.02 \mathrm{~nm}$. This observation is consistent with the existence of two different surface structures on the terraces, but contains no information as to which structures correspond to Fe- and O-terminations.

Faint lineations are visible on the terraces in Figure 5a,b. This modulation of surface height is seen at higher resolution in Figure $5 \mathrm{c}$ with a relief of $0.09 \pm 0.04 \mathrm{~nm}$. This relief is too small to represent monolayer steps (which are, moreover, observed elsewhere on this surface) and is thus consistent with relief caused by differences in termination. At higher resolution (Fig. 6), the modulation has a relief of $\sim 0.06 \pm 0.03 \mathrm{~nm}$ with ridges oriented roughly along $\langle 100\rangle$. Two-dimensional fast Fourier transforms (2D FFTs) of Figures 4 and 5 give a surface periodicity for the linear modulations of $2.2 \pm 0.2 \mathrm{~nm}$. Previous STM imaging (Eggleston and Hochella, 1992; Eggleston, 1999) of terraces resulting from fracture (without annealing) on hematite (001) surfaces did not reveal a periodic surface modulation. However, for these surfaces, imaged "as received" and after cleaning but not resulting from fracture, the periodic modulation has been observed on surfaces cleaned in nitric acid as well as on surfaces cleaned ultrasonically without a nitric acid etch.

The best correspondence between STM images and those calculated using the RTM with different parameter sets occurred with spin restrictions included (see Appendix) and with the $\beta$ values for $\mathrm{B}$ and $\mathrm{C}$ sites set to $1.0 \AA^{-1}$ (Table 3 ). Therefore, all the images presented below use this parameter set. Images calculated using the RTM under simulation conditions of $-500 \mathrm{mV}$ (Fig. 7) also indicate differences in height between different domains. With the Fe-termination high rela- 

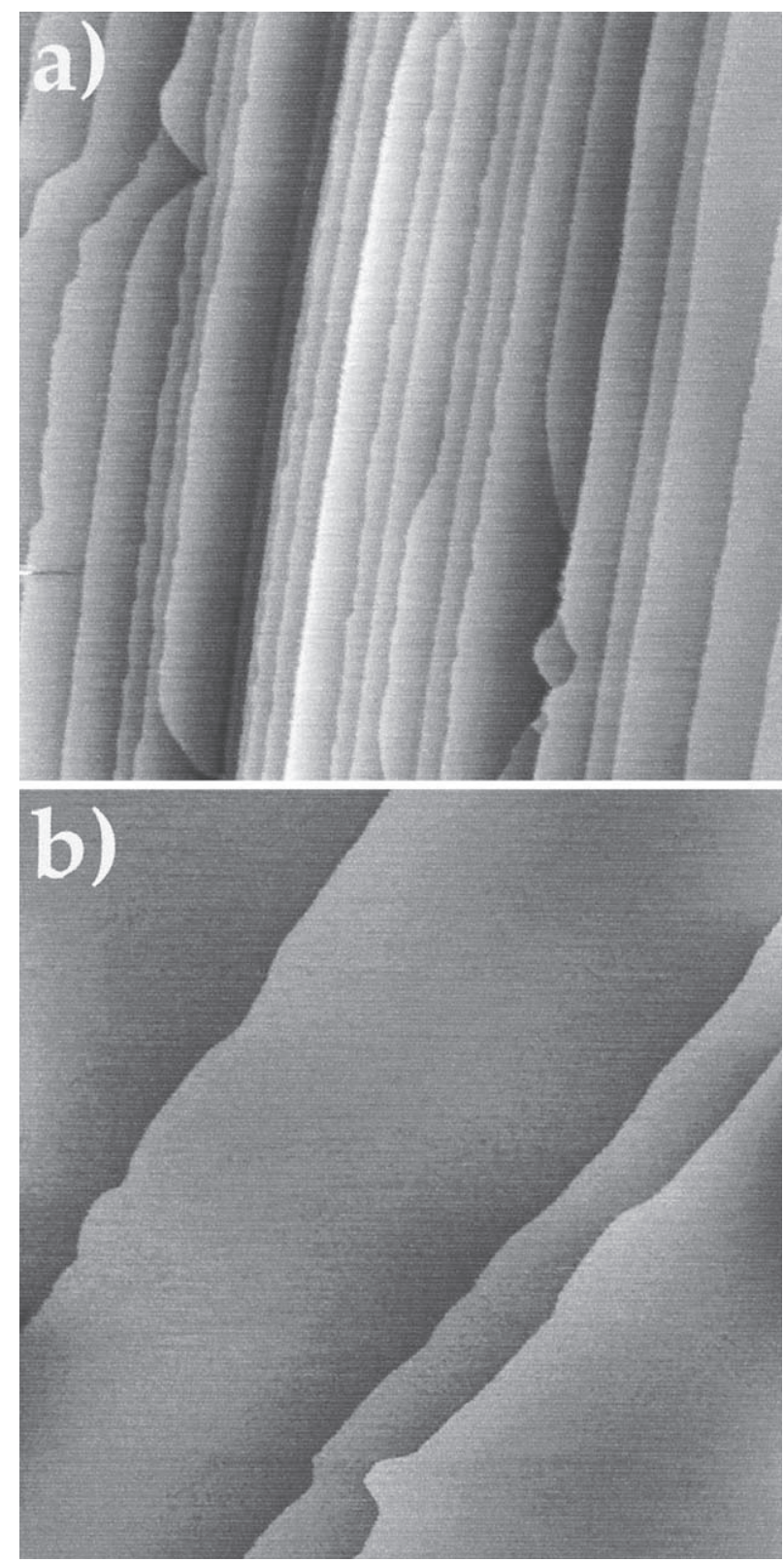

Fig. 4 . $1 \times 1 \mu \mathrm{m}$ STM images. (a) $-534 \mathrm{mV}, 701 \mathrm{pA}$, $\mathrm{z}$ range is 1.0 $\mathrm{nm}$. (b) $-500 \mathrm{mV}, 850 \mathrm{pA}, \mathrm{z}$ range is $0.7 \mathrm{~nm}$. Both images show $\sim 0.23$ $\mathrm{nm}$ step heights and wide terraces on the nitric acid-etched natural hematite $\{001\}$ surface. Height differences on the terraces in larger scans could be artifactually minimized by limited feedback response this problem should be less prevalent for higher-resolution images.

tive to the O-termination (denoted $\mathrm{Fe} / \mathrm{O}$ ) a height difference of only $0.011 \mathrm{~nm}$ was found, whereas with the O-termination higher than the Fe-termination (denoted $\mathrm{O} / \mathrm{Fe}$ ) a height difference of $0.220 \mathrm{~nm}$ was found (Table 3). One height difference is significantly larger than the other, in qualitative agreement with observation (Figs. 4 to 6), suggesting that the topographically high areas on the terraces are regions of Fe-termination.

Figure $8 \mathrm{a}(+500 \mathrm{mV})$ shows a terrace that had aged in air for $1 \mathrm{yr}$ after cleaning. The variations in height between different parts of the image are of the order of $0.09 \pm 0.02 \mathrm{~nm}$ (except for the right side of the image, which has a monolayer step

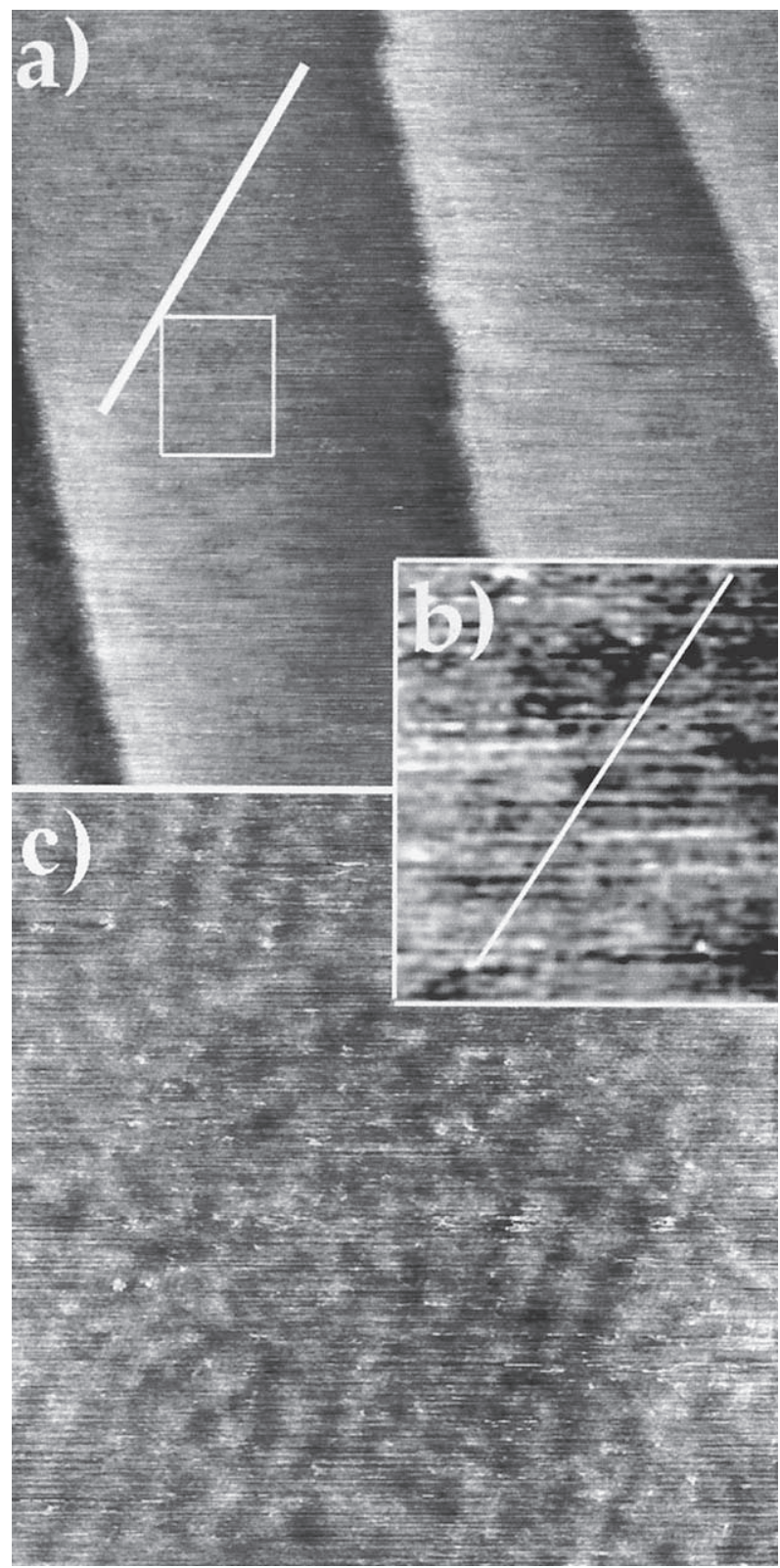

Fig. 5. (a) $215 \times 215 \mathrm{~nm},-534 \mathrm{mV}, 700 \mathrm{pA}$, z range is $0.7 \mathrm{~nm}$; terraces separated by $0.23 \mathrm{~nm}$ steps exhibit a faintly visible lineation (see white line) in a $\langle 100\rangle$ direction; boxed area shows these lineations in (b). (c) $30 \times 30 \mathrm{~nm},-500 \mathrm{mV}, 850 \mathrm{pA}$, z range is $0.3 \mathrm{~nm}$. Semiperiodic features on the terrace imaged in (a). The faint ridges are not parallel to those in (a) because of drift distortion.

marked with arrows). Figure $8 \mathrm{~b}$ is a current image from the boxed area in Figure 8a, and shows two different domains, one characterized by sites $0.5 \mathrm{~nm}$ apart (unit cell scale; rows shown by the white line in Fig. 8b) that correspond to the topographically higher areas in Figure 8a, and one with higher frequency rows rotated $30^{\circ}$ relative to the first domain (dark line in Fig. $8 \mathrm{~b})$ corresponding to the topographically lower regions of Figure 8a. These images again indicate the coexistence of two different structural terminations.

Calculated height and current images for comparison to Figure 8 for $\mathrm{Fe} / \mathrm{O}$ give a height difference of $0.039 \mathrm{~nm}$, and 


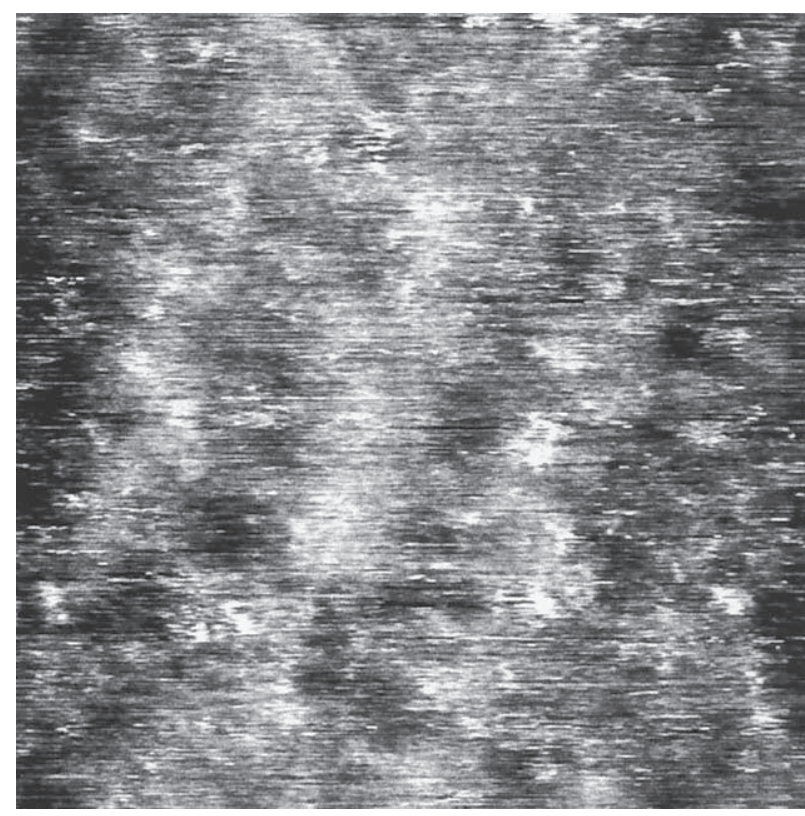

Fig. $6.12 \times 12 \mathrm{~nm}$ image, $-500 \mathrm{mV}$ and $850 \mathrm{pA}, \mathrm{z}$ range is $0.2 \mathrm{~nm}$ Total grayscale is $0.2 \mathrm{~nm}$; surface topographic variation average $0.06 \pm$ $0.03 \mathrm{~nm}$. The period of the surface modulation is $\sim 2.2 \pm 0.2 \mathrm{~nm}$ (based on both 1D and 2D FFT analyses of the images, although the peaks are not continuous).

with $\mathrm{O} / \mathrm{Fe}$ the height difference is $0.194 \mathrm{~nm}$ (Fig. 9, Table 3). Because the measured $0.09 \pm 0.02 \mathrm{~nm}$ height difference is small relative to $0.23 \mathrm{~nm}$, this is again most consistent with the Fe-termination being topographically high relative to the Otermination in Figure 8. The topographically high areas in Figure 8a show a strong $0.5 \mathrm{~nm}$ periodicity (Fig. 8b); for the calculations, Figure 9c $(\mathrm{Fe} / \mathrm{O})$ most closely matches Figure $8 \mathrm{~b}$, but we cannot reproduce the $30^{\circ}$ rotation of rows between domains because the next $\mathrm{Fe}$ layer below the $\mathrm{B}$ and $\mathrm{C}$ sites does not have a similar current to the $\mathrm{B}$ and $\mathrm{C}$ sites. We should reiterate that our RTM only accounts for electrons transmitted to the STM tip through resonators, and not for current passing directly from the substrate to the tip. This could account for differences between the RTM and STM images.

Figure 10, taken in air, shows a step-like feature with segments and macrokinks (to use a term normally applied only to steps) parallel to $\langle 100\rangle$ directions. Height measurements reveal that the "step," however, is only $0.11 \pm 0.04 \mathrm{~nm}$ high, within error of the depth of the deepest "dimples" in the terraces to

Table 3. Height differences between domains.

\begin{tabular}{|c|c|c|c|c|c|c|}
\hline & \multicolumn{2}{|c|}{$+500 \mathrm{mV}$} & \multicolumn{2}{|c|}{$-500 \mathrm{mV}$} & \multicolumn{2}{|c|}{$-900 \mathrm{mV}$} \\
\hline & $\mathrm{Fe} / \mathrm{O}$ & $\mathrm{O} / \mathrm{Fe}$ & $\mathrm{Fe} / \mathrm{O}$ & $\mathrm{O} / \mathrm{Fe}$ & $\mathrm{Fe} / \mathrm{O}$ & $\mathrm{O} / \mathrm{Fe}$ \\
\hline $\mathrm{SpU} / 1.2$ & 0.115 & 0.117 & 0.041 & 0.195 & 0.039 & 0.194 \\
\hline $\mathrm{SpR} / 1.2$ & 0.039 & 0.194 & 0.011 & 0.220 & 0.011 & 0.221 \\
\hline $\mathrm{SpU} / 1.0$ & 0.020 & 0.104 & 0.003 & 0.228 & 0.000 & 0.230 \\
\hline $\mathrm{SpR} / 1.0$ & -0.003 & 0.233 & -0.003 & 0.233 & -0.003 & 0.233 \\
\hline
\end{tabular}

$\mathrm{SpU}$ and $\mathrm{SpR}$ denote spin allowed and spin forbidden, respectively. $/ 1.2$ and $/ 1.0$ denote the $\beta$ values used for the $\mathrm{B}$ and $\mathrm{C}$ sites, respectively (A sites on Fe terminations are always 1.2; see appendix).
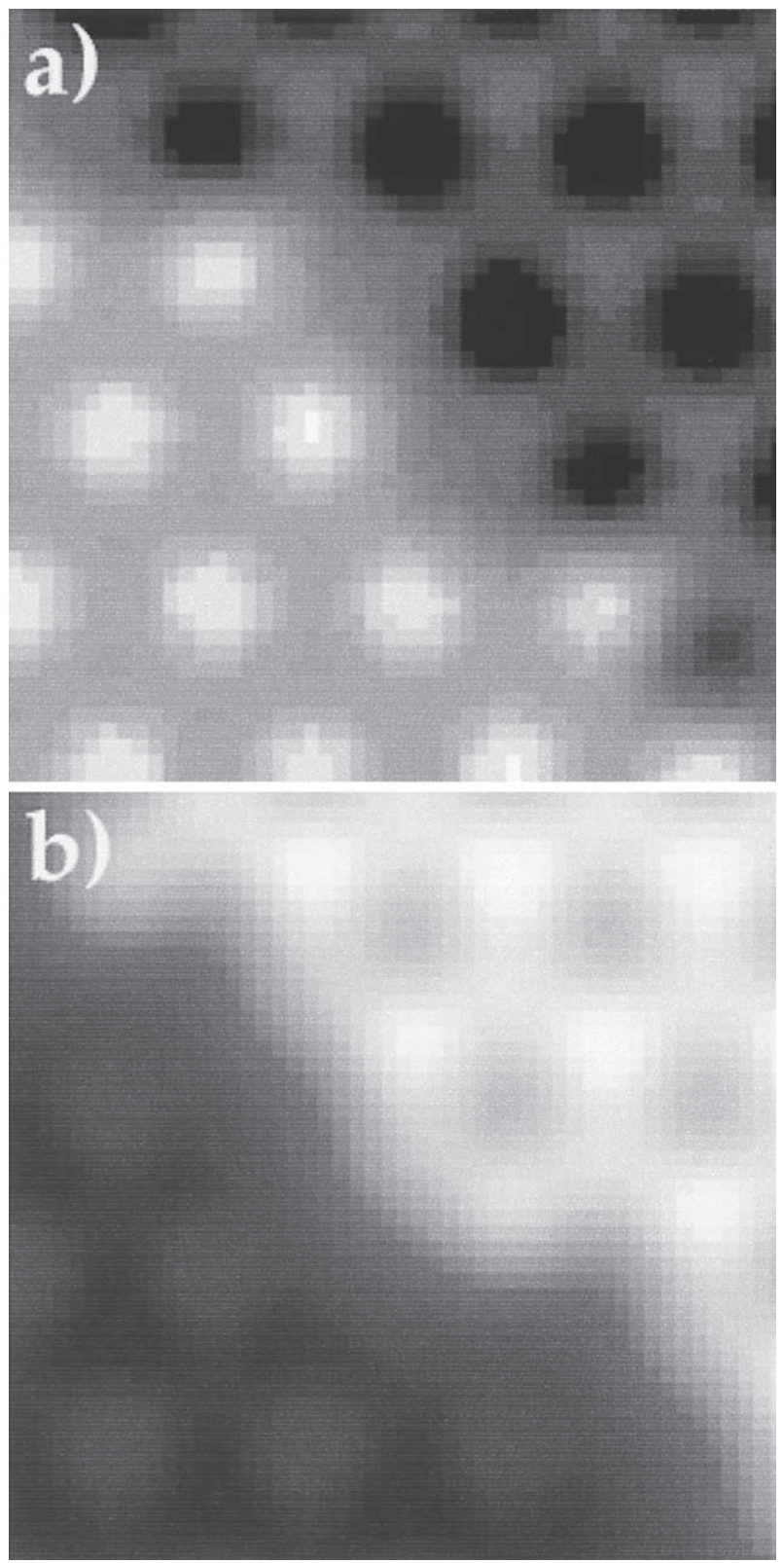

Fig. 7. Images (both $2 \times 2 \mathrm{~nm}$ ) calculated using the RTM for -500 $\mathrm{mV}$ conditions, for (a) Fe-termination high, O-termination low and (b) O-termination high, Fe-termination low. The total grayscale in (a) is $0.02 \mathrm{~nm}$, and in (b) is $0.290 \mathrm{~nm}$. In (a), the topographically high area shows $\mathrm{B}$ sites most prominently, and the $\mathrm{B}$ and $\mathrm{C}$ sites are visible in the topographically low area. In (b), B and C sites are faintly visible in both terminations.

either side of the feature. These heights are too small to represent a full octahedral layer step, implying that they are caused by differences in terrace atomic structure.

\subsection{STM in DDI Water}

Figure 11 shows a series of in situ STM images at positive sample bias (tunneling from tip to surface). A single site stands out in Figure 11a relative to the others in the upper part of the 

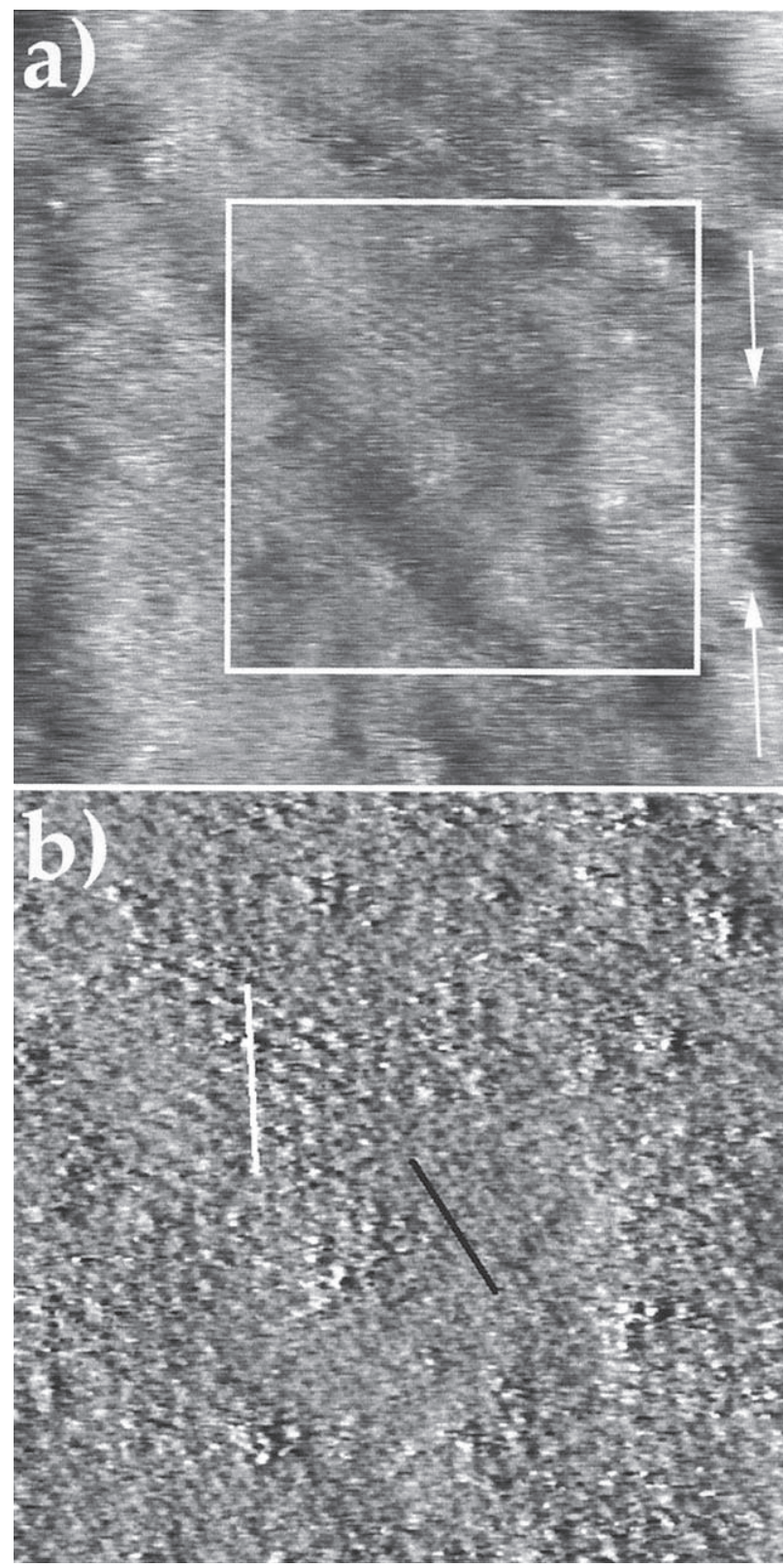

Fig. 8. (a) $20 \times 20 \mathrm{~nm}$ height image taken at $+500 \mathrm{mV}, 500 \mathrm{pA}, \mathrm{z}$ range is $1.0 \mathrm{~nm}$. Variations in local height are evident, similarly to Figures 4 through 6 but not in a well-ordered pattern. Arrows point to an octahedral layer step. The white box shows the area given as a current image in (b). (b) $12 \times 12 \mathrm{~nm}$ current contrast image, total relief in grayscale is $250 \mathrm{pA}$. Two structurally different domains; atomic rows in the topographically high domains are delineated by a white line, and atomic rows in the topographically low domains are delineated by a black line.

image, but in the lower part, faint "rings" are visible. The "rings" are most simply (but tentatively) interpreted as B and C sites. The bright spots in the upper part of Figure 11a are structurally contiguous with a site on the rings in the lower part of the image, possibly the "B" site. Figure 11a is similar to (but better resolved than) Figure $8 \mathrm{~b}$, in which the brighter sites appear every $0.5 \mathrm{~nm}$ in rows rotated $30^{\circ}$ relative to the higher frequency rows (this relationship is indicated by the white lines in Fig. 11a). At lower positive bias (Fig. 11b), we see ring structures and sites within them. The dimple in Figure $11 \mathrm{~b}$ is $\sim 0.05 \mathrm{~nm}$ deep. Calculated images at $+250 \mathrm{mV}$ give a height difference of only $0.015 \mathrm{~nm}$ for Fe/O. Figures $11 \mathrm{c}$ and $11 \mathrm{~d}$, at small positive bias, show that the individual sites are more similar to each other than in Figure 11a or b.

A series of calculated images for comparison to Figure 11 is given in Figure 12. Figure 12a, for $+500 \mathrm{mV}$, does not agree well with Figure 11a because the brightest site is the B site in the O-termination, but the A site in the Fe-termination, whereas in Figure 11a one site (B?) simply appears to change brightness. Figure $12 \mathrm{~b}$, for $+250 \mathrm{mV}$, shows ring structures (B and $\mathrm{C}$ sites) that on the Fe-termination contain an A site, similar to Figure 11b. Figures 12c (for $+75 \mathrm{mV}$ ) and $12 \mathrm{~d}$ (for $+50 \mathrm{mV}$ ) show that within the RTM the B sites dominate both terminations at low positive bias.

Indeed, Figures $12 \mathrm{~b}$ and $\mathrm{d}$ are most reminiscent of Figure 11a in showing a change in the brightness of $\mathrm{B}$ sites with a change in domain. Thus, within our RTM, the A site predominates on the Fe-termination at $+500 \mathrm{mV}$ but the $\mathrm{B}$ site predominates on the Fe-termination at lower positive bias (and at negative biases). This concept of "cross-over" between which sites predominate is illustrated in Figure 13, which shows calculated currents through each of the A, B, and C sites for different sets of RTM parameters. For some parameter sets, the current through the A site is equal to that through $\mathrm{B}$ and sometimes $\mathrm{C}$ sites at particular crossover voltages that are very sensitive to the spin restrictions and $\beta$ values used in the RTM. It should also be remembered that these site-specific currents do not include the additive effects of a tip "feeling" several different sites simultaneously, as is the case for the calculated images, and so do not match the calculated images. Because of the sensitivity of crossover to specific parameter values, it is not surprising that the STM images at about $+500 \mathrm{mV}$ more closely match the calculated images for lower positive bias. The B sites do not have the same current everywhere because of surface structural relaxation effects caused by the presence of A sites that affect B site position.

Figure 14 shows in-situ STM current contrast images under negative bias conditions (tunneling from sample to tip). Figure $14 \mathrm{a}$, a region in which considerable apparent topography is found, shows in most places a simple pattern in which a doublet (presumably B and C sites) predominates (Fig. 14b). Figure 14c shows a place in which a domain with a single site every $0.5 \mathrm{~nm}$ coexists with a domain similar to that in Figure 14a. Because these are current images, height differences cannot be measured directly. However, the features of these images compare favorably with those calculated in Figure 7.

\section{4. $\mathrm{STM}$ in $\mathrm{pH} 1 \mathrm{HCl}$}

Two images (Fig. 15), taken as part of a continuous image sequence in situ in a $\mathrm{pH} 1 \mathrm{HCl}$ solution, are included to show the general reproducibility of the topographically higher and lower domains (the height difference between domains is 0.05 $\pm 0.02 \mathrm{~nm}$ ), but also to show that from image to image, there are variations in the high-resolution details because of changes in the STM tip characteristics. In both images, faint ring structures are visible in both the lower and higher domains. Topographically high areas have a site that stands out with higher 


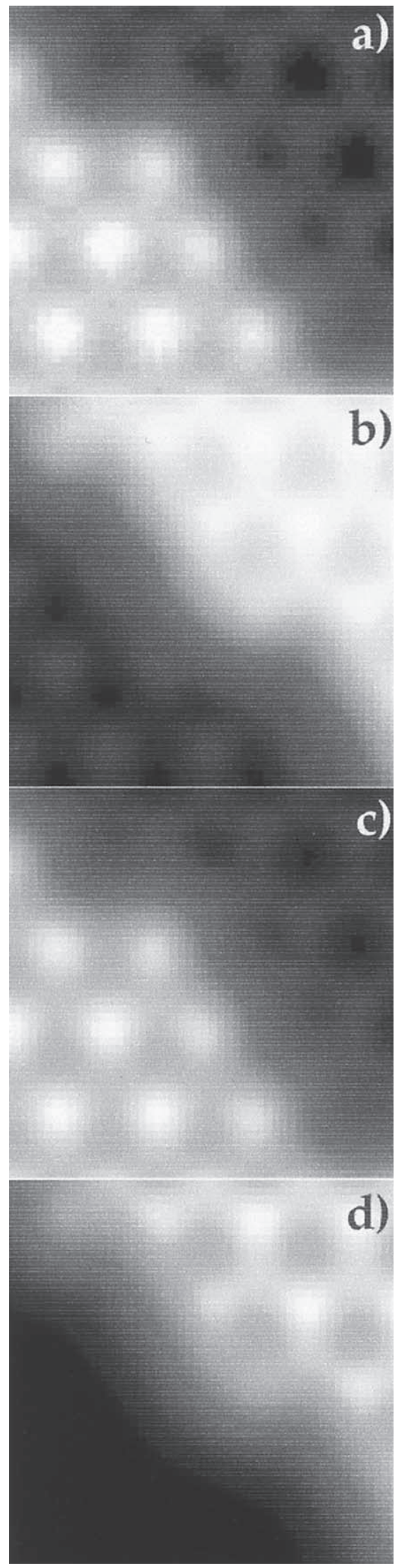

Fig. 9. Images (all $2 \times 2 \mathrm{~nm}$ ) calculated with the RTM for $+500 \mathrm{mV}$ with a tip height of $0.4 \mathrm{~nm}$. (a) and (b) are height contrast images, and (c) and (d) are corresponding current contrast images for a tip height of $0.4 \mathrm{~nm}$. In all images, the $\mathrm{Fe}$ termination shows $\mathrm{A}$ sites and the $\mathrm{O}$-termination shows $\mathrm{B}$ and $\mathrm{C}$ sites. (a) $\mathrm{Fe} / \mathrm{O}$, total relief in grayscale is $0.08 \mathrm{~nm}$. (b) $\mathrm{O} / \mathrm{Fe}$, total relief in grayscale is $0.299 \mathrm{~nm}$. Absolute tunneling currents are arbitrary because in the experiment we do not know the tip height exactly, but the calculated current should scale with measured currents; in (c) $\mathrm{Fe} / \mathrm{O}$, variation is $46 \%$ of the highest current (if the highest current is $1 \mathrm{nA}$, then the lowest is $540 \mathrm{pA}$ ), and in (d) $\mathrm{O} / \mathrm{Fe}$, variation is $97 \%$ (if the highest current is $1 \mathrm{nA}$, then the lowest is $30 \mathrm{pA}$ ). In experimental images, feedback keeps the tip tracking the surface so that truly constant height is not in practice achieved and the measured current contrast will be less than in the calculated images.

tunneling current and therefore with greater height (similar to Fig. 11a). These sites appear to be contiguous with sites on the rings in the topographically lower areas. This is in qualitative agreement with Figure 16, the calculated image for $-900 \mathrm{mV}$ conditions.

During this and other image sequences of the hematite surface at $\mathrm{pH} \mathrm{1,} \mathrm{no} \mathrm{clear} \mathrm{evidence} \mathrm{for} \mathrm{dissolution} \mathrm{was} \mathrm{observed.}$ For example, there is a topographically low area whose outlines (white lines in Fig. 15) do not change between these and other images in the sequence. This sequence lasted for $1 \mathrm{~min}$, but no atomic scale change in the outline of this domain was observed. This suggests that the hematite (001) surface is quite inert at $\mathrm{pH}$ 1 , both to dissolution and to surface diffusion of Fe from A site to A site. For comparison, the steady-state dissolution rate of hematite (Samson et al., 2000) is consistent with, on average, removal of only one Fe atom from this image area every $12 \mathrm{~h}$ !

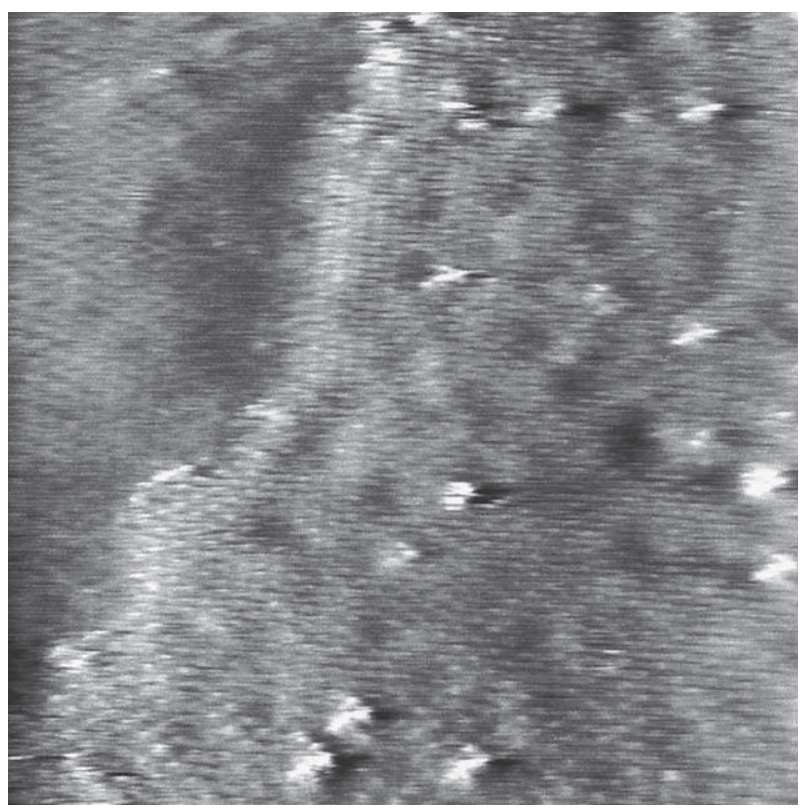

Fig. 10. $20 \times 20 \mathrm{~nm}$ image taken at $-600 \mathrm{mV}, 500 \mathrm{pA}, \mathrm{z}$ range is $0.4 \mathrm{~nm}$; images shows numerous "dimples" and high-current defects in addition to a step-like feature that is nevertheless only $0.11 \pm 0.04 \mathrm{~nm}$ high. Because the defects show a clear multiple tip artifact, and because of other distortions in the image, we refrain from interpretation of the unit-cell-scale structure. 


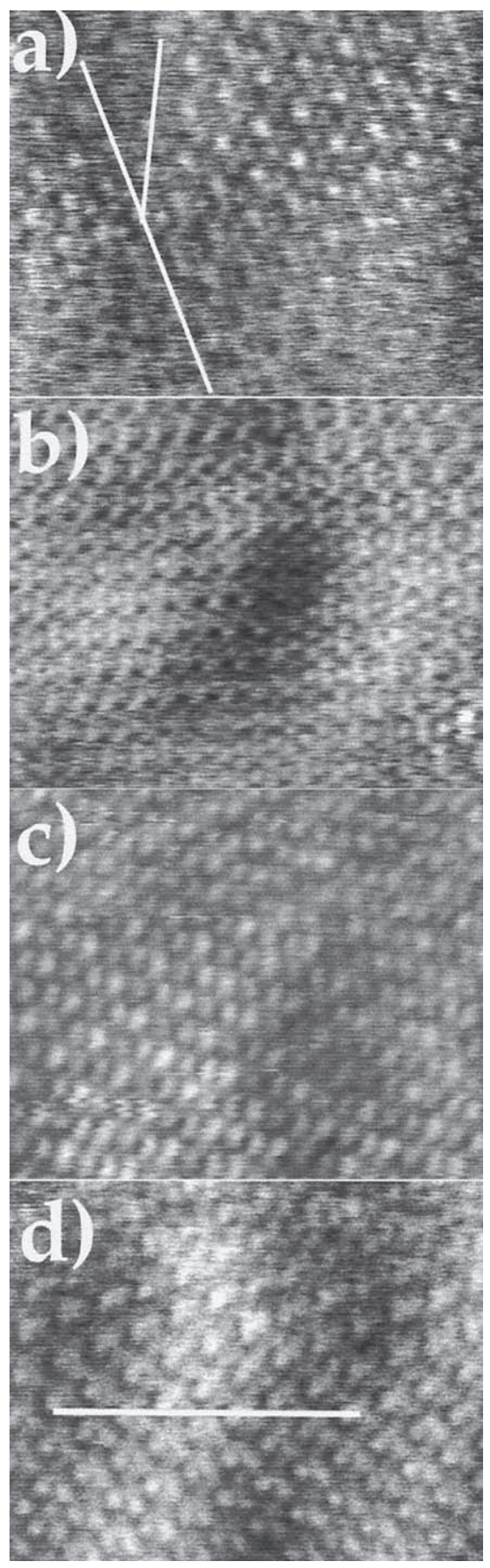

Fig. 11. A series of $6 \times 5 \mathrm{~nm}$ STM images taken in water at progressively decreasing positive bias voltages (tunneling from tip to surface). (a) $+506 \mathrm{mV}, 1.2 \mathrm{nA}$, grayscale is $500 \mathrm{pA}$. (b) $+250 \mathrm{mV}, 400$ $\mathrm{pA}, \mathrm{z}$ range is $0.12 \mathrm{~nm}$. (c) $+74 \mathrm{mV}, 900 \mathrm{pA}$, grayscale is $554.6 \mathrm{pA}$ (d) $+33.3 \mathrm{mV}, 1.2 \mathrm{nA}$, grayscale is $255.9 \mathrm{pA}$. The height image (b) has a simultaneously acquired current image with a vertical scale of $400 \mathrm{pA}$ and that looks identical to (b). The horizontal bar in d indicates a change in tip characteristics during the scan; well-resolved sites are seen below the bar, but a broader, irregular single peak is seen above the bar.

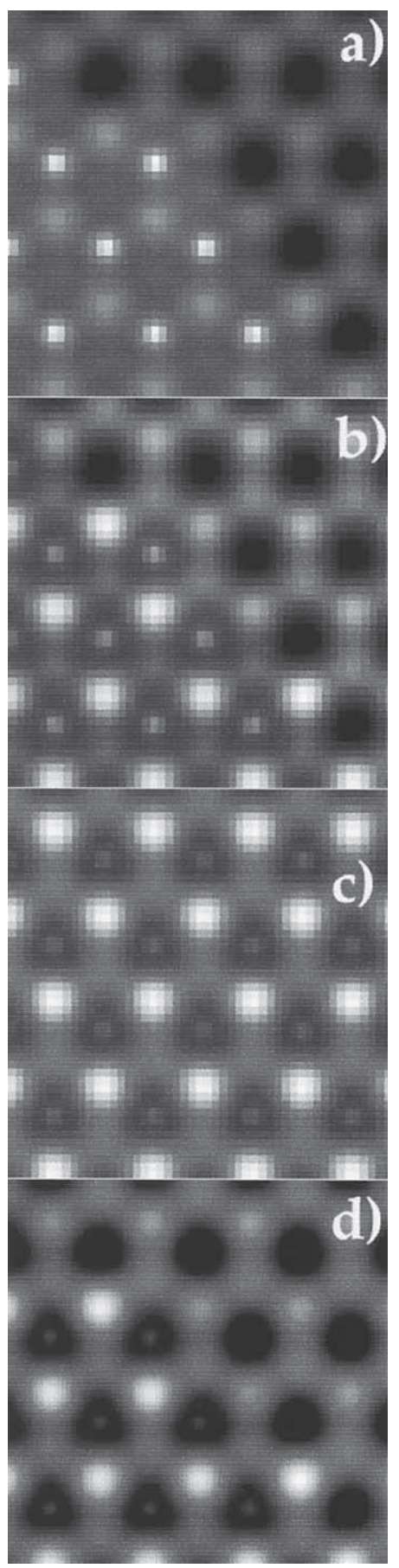

Fig. 12. Calculated images for comparison to Figure 11. These are calculated with the tip very close to the surface, which has the effect of making the individual sites more distinct from each other. (a) Current contrast (41\%) image of $\mathrm{Fe} / \mathrm{O}$ at $+500 \mathrm{mV}, 0.02 \mathrm{~nm}$ tip height. In the Fe-termination (lower left), A sites predominate, whereas in the Otermination the $\mathrm{B}$ and $\mathrm{C}$ sites predominate. (b) Current contrast image of $\mathrm{Fe} / \mathrm{O}$ for $+250 \mathrm{mV}$, tip height $0.02 \mathrm{~nm}$. B sites predominate in both terminations, but are brighter within the Fe termination (lower left). (c) Current contrast (53\%) image, for $+75 \mathrm{mV}$, Fe termination, tip height $0.02 \mathrm{~nm}$. All three sites are visible, but the B sites again predominate. (d) Current contrast $(56 \%)$ image, for $+50 \mathrm{mV} \mathrm{Fe} / \mathrm{O}$. B sites again predominate. 


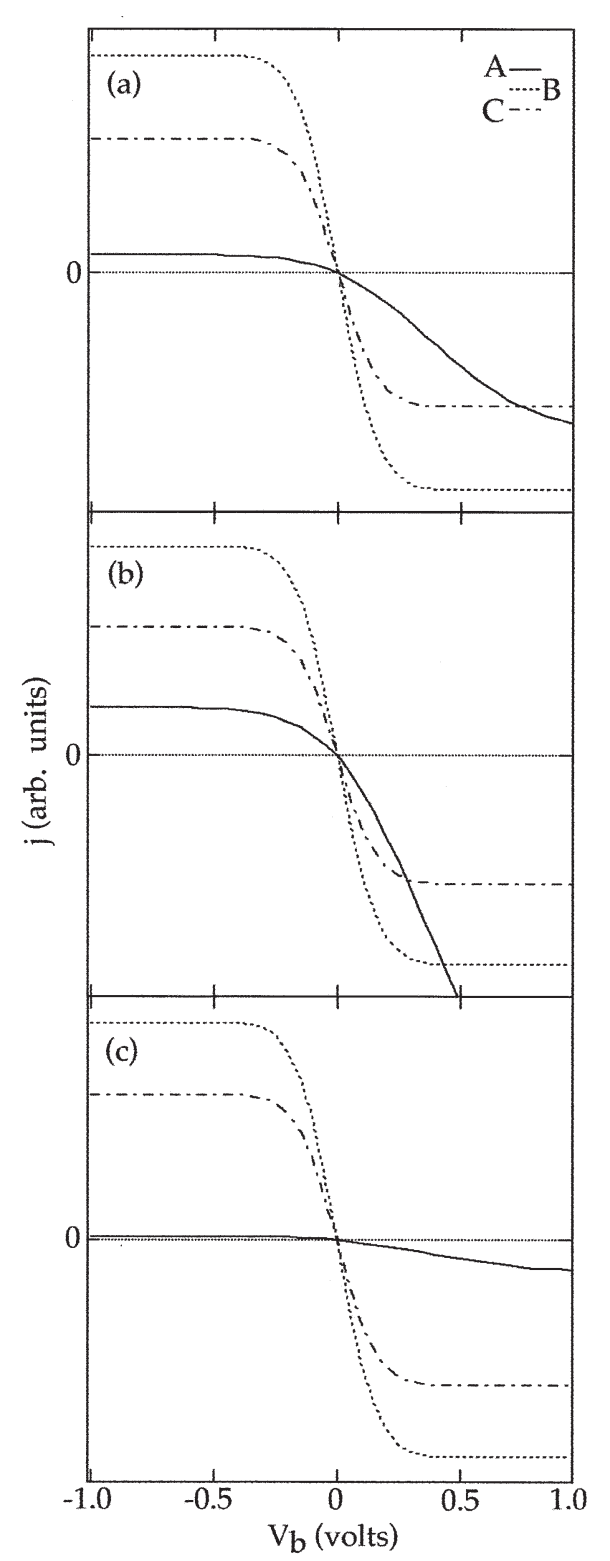

Fig. 13. Calculated current through individual A, B, and C sites for an Fe-termination as a function of bias voltage for different RTM parameter sets. Tip height is $0.4 \mathrm{~nm}$ in all cases. (a) Spin forbidden, $\beta$ values all set to $1.2 \AA^{-1}$. (b) Spin allowed, $\beta$ values all $1.2 \AA^{-1}$. (c) Spin forbidden, $\beta$ values set to $1.2 \AA^{-1}$ for $\mathrm{A}$ sites and $1.0 \AA^{-1}$ for $\mathrm{B}$ and $\mathrm{C}$ sites.

\subsection{Origin of the Periodic Surface Modulations}

We have not yet attempted a systematic study of different preparation procedures to definitively determine the origin of the modulations (Figs. 4 to 6). Calculations made by Wang et al. (1998) suggest that the Fe- and O-terminations have substantially different surface structural relaxations. Although these relaxations may be ameliorated somewhat by the presence of adsorbed water and hydroxyl, it is reasonable to suppose that significant strain energy may occur between domains. We speculate that such strain may achieve a minimum energy by distributing itself in a periodic manner across the surface.

\subsection{Effects of Impurities and Defects}

Many images (e.g., Figs. 10 and 14) show reproducible topographic modulations without any apparent change in image character consistent with a change in termination. A significant concern, therefore, is whether local conductivity effects lead to the apparent $<0.1 \mathrm{~nm}$ surface relief instead of O- vs. Feterminations. A charged impurity defect could create a local potential that bends bands locally and leads to apparent height differences to an extent akin to a modulation of the bias voltage. Based on our ICP-MS analysis of impurities, however, we calculate that we should see only $\sim 1.1$ impurity defects per $20 \times 20 \mathrm{~nm}$ image. In general, we see considerably more height modulations ("dimples" and "bumps") than this. In Figure 10, for example, there are $\sim 60$ dimples and bumps in a $20 \times 20 \mathrm{~nm}$ area. Shuey (1975) reviewed earlier literature showing that there are insufficient oxygen vacancies in natural hematites to compete with impurities as contributors to conductivity; our conductivity results do not allow a significantly higher oxygen vacancy population than impurity concentration. We are forced to conclude that most of the topographic modulations are not related to impurities or bulk defects unless there is a concentrated impurity that we did not detect in ICP-MS and that has no effect upon conductivity.

If the topographic modulations are not changes in structural domain, then the only remaining possibilities are that they represent feedback oscillations of STM tip height with an unknown cause, or that $\mathrm{Fe}^{3+}$ ions in an "adsorbed" state on the surface, in sites distinct from those of an ordered termination (Samson and Eggleston, 1998; Samson et al., 2000), disturb the local potential but are not visible as distinct atoms in the images. It is also possible that defective areas on the surface, with a different characteristic current than ordered areas, initiate feedback oscillations in tip height (e.g., see defective areas in Fig. 14a).

\section{CONCLUSIONS}

Our STM images are consistent with the coexistence of Feand O-terminations on hematite (001) surfaces. There are two different possible domain boundaries: $\mathrm{Fe} / \mathrm{O}$ and $\mathrm{O} / \mathrm{Fe}$. These boundaries appear to have substantially different heights in STM images, in qualitative agreement with height differences calculated using the RTM. Despite the fairly ubiquitous nature of the small coexisting domains of Fe- and O-termination, there are many other topographic modulations that are not attributable to differences in termination. We speculate that these "dimples" and "bumps" are caused by the presence of surface Fe in an adsorbed state as well as feedback oscillations of the tip induced by defective areas. Finally, the RTM is qualitatively successful in reproducing many (but not all) of the features of the STM images, including height differences between domains as well as structures within different domains.

This study is a step toward a more complete picture of hematite surface structure, and serves as part of a baseline for future understanding of structures resulting from adsorption. For example, an adsorbed organic molecule chelating a surface iron site is likely to change the resonance and reorganization energies for that site and thus change not only the electron transfer characteristics, but also the site appearance in STM 

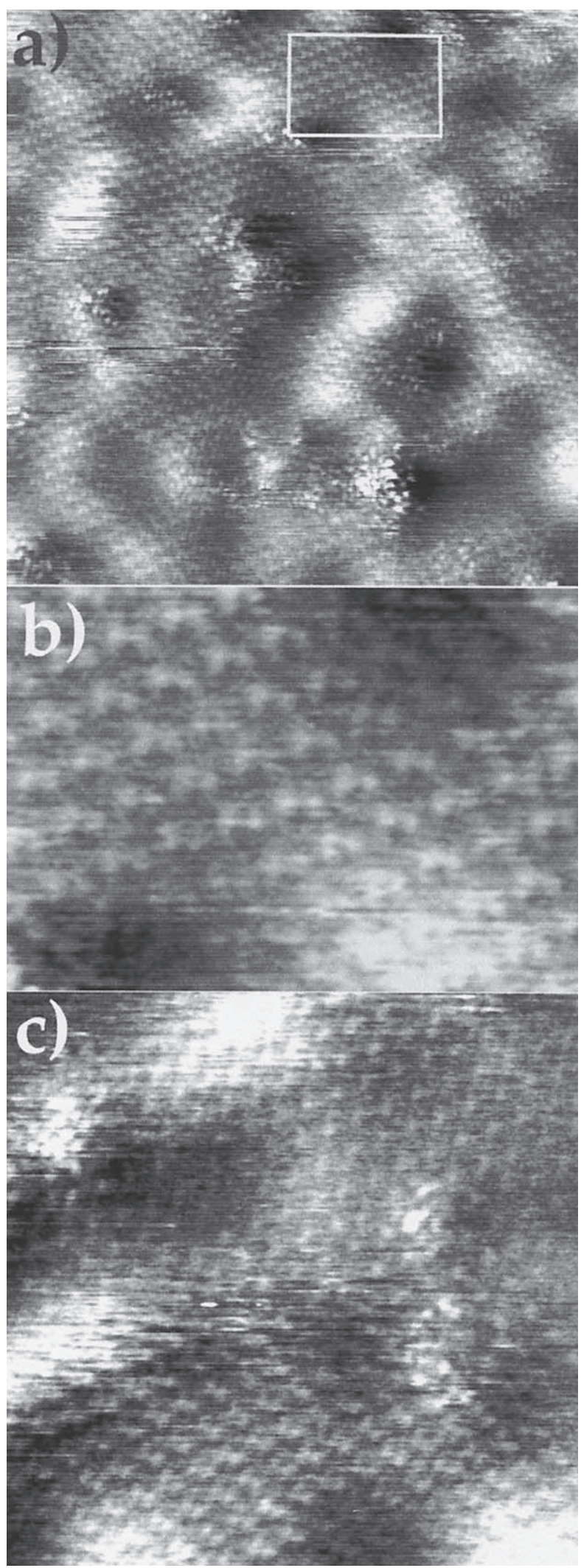

Fig. 14. Current STM images taken in DDI water under negative bias conditions. (a) $20 \times 20 \mathrm{~nm},-600 \mathrm{mV}, 700 \mathrm{pA}$, grayscale is $600 \mathrm{pA}$. Most of the image area exhibits a "doublet" pattern, similar to a "ring" pattern, that is consistent with imaging of " $\mathrm{B}$ " and " $\mathrm{C}$ " sites (Fig. 2). (b)
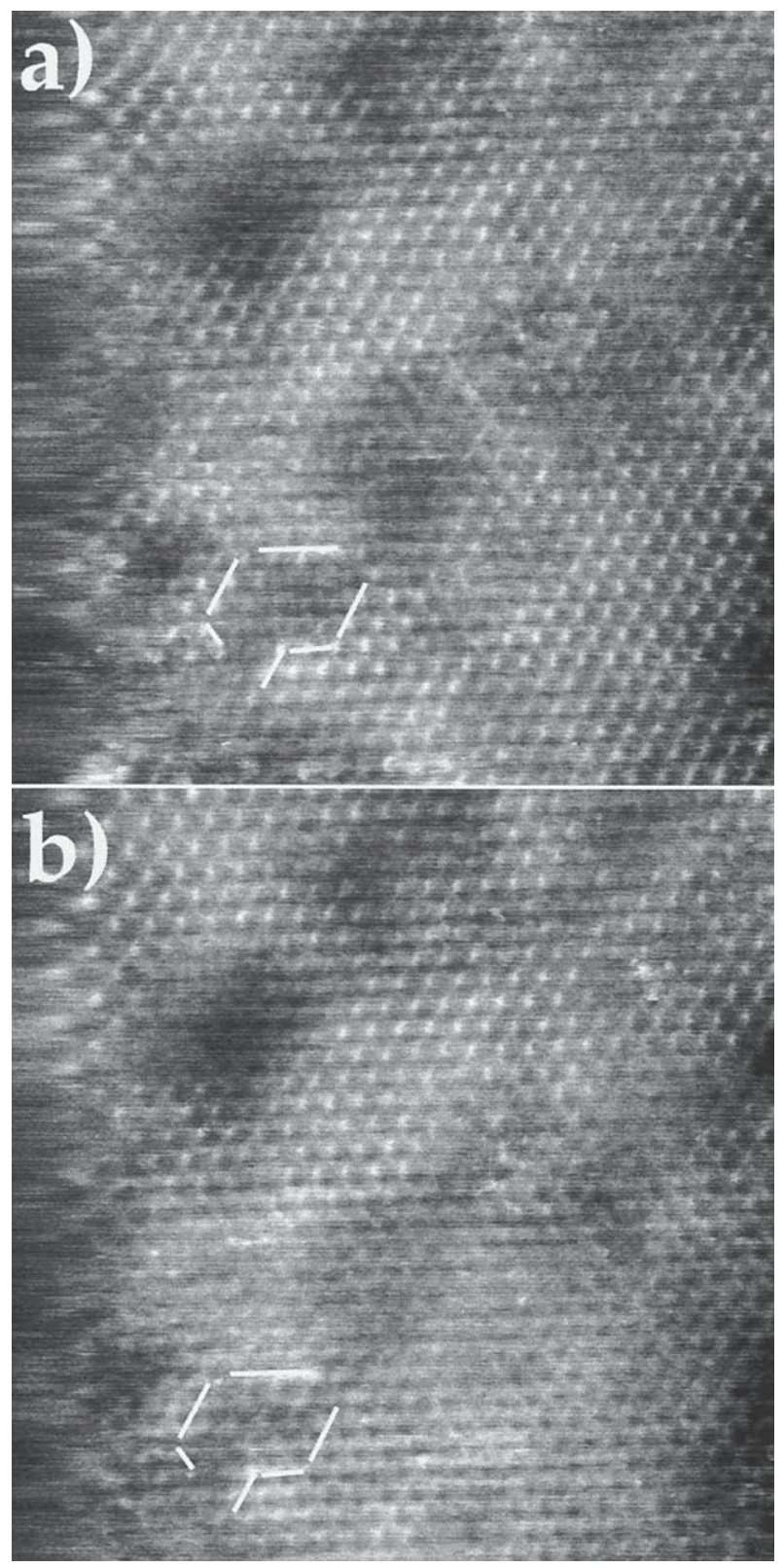

Fig. $15.10 \times 10 \mathrm{~nm}$ height STM images taken in $\mathrm{pH} 1 \mathrm{HCl}$, both at $-900 \mathrm{mV}, 1.9 \mathrm{nA}, \mathrm{z}$ range is $0.12 \mathrm{~nm}$. Because imaging is taking place in a high-conductivity solution, actual tunneling currents are probably lower than the setpoint current of $1.9 \mathrm{nA}$ because of leakage currents.

imaging. Dissolution may not be as simple as detachment of Fe centers from kink sites along monolayer steps, but may involve more complex "half-step" processes at the edges of termination domains as well. Finally, in light of these and other observations of surface structures that can change with conditions, it becomes more difficult to assume that the site density used in

$5 \times 3.3 \mathrm{~nm}$, zoomed area of (a). (c) $10 \times 10 \mathrm{~nm},-500 \mathrm{mV}, 700 \mathrm{pA}$, grayscale is $255.9 \mathrm{pA}$. This image was taken on the same surface as in (a), but in this case two domains are visible in the upper and lower parts of the image. The separation between the two is not parallel to the scan direction in large images of this area (not shown). 


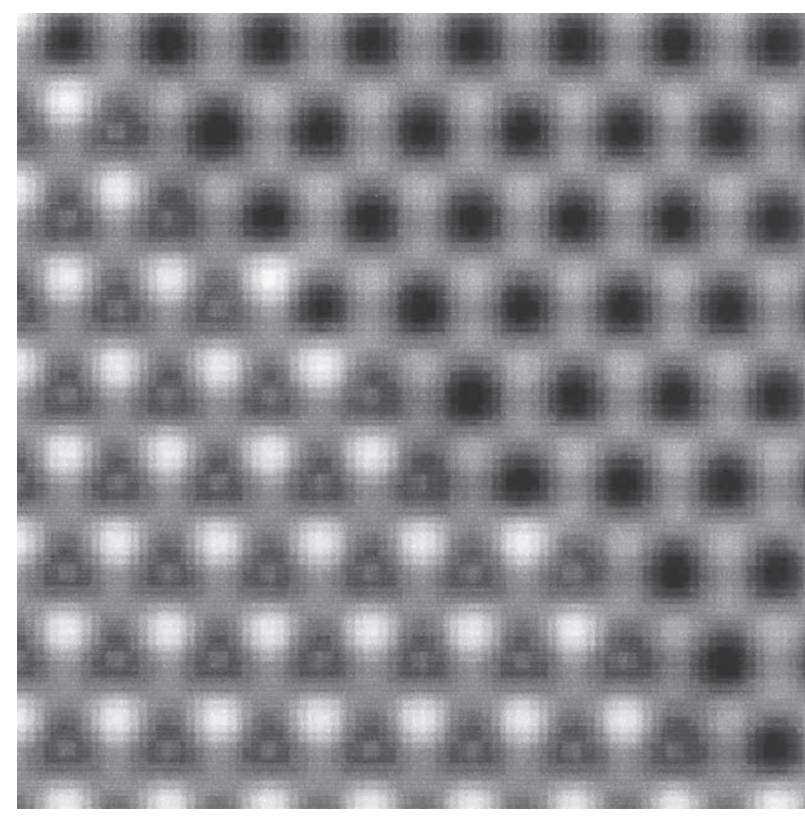

Fig. 16. Calculated constant current image for $-900 \mathrm{mV}$, a starting tip height of $0.2 \mathrm{~nm}$, and an area of $4 \times 4 \mathrm{~nm}$. Total grayscale is 0.053 $\mathrm{nm}$. Within the Fe-termination, in the lower left, A sites are faintly visible and $\mathrm{B}$ sites are brighter than in the O-termination (upper right). It should be remembered that $-900 \mathrm{mV}$ is in a voltage region where the limitations of the RTM with regard to neglecting direct substrate-to-tip current may affect the image.

adsorption modeling can be safely assumed constant without consideration of sample history.

Acknowledgments - This material is based upon work supported by the National Science Foundation under Grant No. EAR-9875830. Pacific Northwest National Laboratory is operated for the DOE by Battelle Memorial Institute under Contract DE-AC06-76RLO 1830. We thank Mr. Drew Cornia for helping with the STM. We also thank three anonymous reviewers for comments that were useful in improving the manuscript.

\section{Associate editor: U. Becker}

\section{REFERENCES}

Afonso M. D. S., Morando P. J., Blesa M. A., Banwart S., and Stumm W. (1990) The reductive dissolution of iron oxides by ascorbate. $J$. Coll. Interf. Sci. 138, 74-82.

Anderman M. and Kennedy J. H. (1988) Iron oxide $\left(\mathrm{Fe}_{2} \mathrm{O}_{3}\right)$. In Semiconductor Electrodes (ed. H. O. Finklea), Vol. 55, pp. 147-202. Elsevier, Amsterdam.

Barrón V., Galvez N., Hochella M. F. J., and Torrent J. (1997) Epitaxial overgrowth of goethite on hematite synthesized in phosphate media: A scanning force and transmission electron microscopy study. Am. Mineral. 82, 1091-1100.

Becke A. D. (1993) A new mixing of Hartree-Fock and local densityfunctional theories. J. Chem. Phys. 98, 1372-1377.

Becker U., Hochella M. F. J., and Aprà E. (1996) The electronic structure of hematite $\{001\}$ surfaces: Applications to the interpretation of STM images and heterogeneous surface reactions. Am. Mineral. 81, 1301-1314.

Bosman A. J. and van Daal H. J. (1970) Small polaron versus band conduction in some transition-metal oxides. Adv. Phys. 19, 1-118.

Brown G. E. J., Henrich V. E., Casey W. H., Clark D. L., Eggleston C. M., Felmy A., Goodman D. W., Graetzel M., Maciel G., McCarthy M. I., Nealson K. H., Sverjensky D. A., Toney M. F., and
Zachara J. M. (1999) Metal oxide surfaces and their interactions with aqueous solutions and microbial organisms. Chem. Rev. 99, 77-174.

Burton W. K., Cabrera N., and Frank F. C. (1951) The growth of crystals and the equilibrium structure of their surfaces. Phil. Trans. Royal Soc. Lond. A. 243, 40-358.

Chambers S. A. and Yi S. I. (1999) Fe termination for $\alpha-\mathrm{Fe}_{2} \mathrm{O}_{3}(0001)$ as grown by oxygen-plasma-assisted molecular beam epitaxy. Surf. Sci. Lett. 439, L785-L791.

Clark T., Chandrasekhar J., Spitznagel G. W., and Schleyer P. V. (1983) Efficient diffuse function-augmented basis-sets for anion calculations. 3. The 3-21+G basis set for 1st-row elements, Li- F. J. Computa. Chem. 4, 294-301.

Condon N. G., Leibsle F. M., Lennie A. R., Murray P. W., Parker T. M., Vaughan D. J., and Thornton G. (1998) Scanning tunneling microscopy studies of $\alpha-\mathrm{Fe}_{2} \mathrm{O}_{3}(0001)$. Surf. Sci. 397, 278-287.

Condon N. G., Leibsle F. M., Lennie A. R., Murray P. W., Vaughan D. J., and Thornton G. (1995) Biphase ordering of iron oxide surfaces. Phys. Rev. Lett. 75, 1961-1964.

Condon N. G., Murray P. W., Leibsle F. M., Thornton G., Lennie A. R., and Vaughan D. J. (1994) $\mathrm{Fe}_{3} \mathrm{O}_{4}(111)$ termination of $\alpha-\mathrm{Fe}_{2} \mathrm{O}_{3}(0001)$. Surf. Sci. Lett. 310, L609-L613.

Coston J. A., Fuller C. C., and Davis J. A. (1995) $\mathrm{Pb}^{2+}$ and $\mathrm{Zn}^{2+}$ adsorption by a natural aluminum- and iron-bearing surface coating on an aquifer sand. Geochim. Cosmochim. Acta 59, 3535-3547.

Dzombak D. A. and Morel F. M. M. (1990) Surface Complexation Modeling. John Wiley, New York.

Eggleston C. M. (1999) The surface structure of $\alpha-\mathrm{Fe}_{2} \mathrm{O}_{3}$ (001) by scanning tunneling microscopy: Implications for interfacial electron transfer reactions. Am. Mineral. 84, 1061-1070.

Eggleston C. M. and Hochella M. F. J. (1992) The structure of hematite (001) surfaces by scanning tunneling microscopy: Image interpretation, surface relaxation, and step structure. Am. Mineral. 77, 911922.

Faust B. C., Hoffmann M. R., and Bahnemann D. W. (1989) Photocatalytic oxidation of sulfur dioxide in aqueous suspensions of $\alpha-\mathrm{Fe}_{2} \mathrm{O}_{3}$. J. Phys. Chem. 93, 6371-6381.

Frisch M. J., Trucks G. W., Schlegel H. B., et al. (1998) Gaussian98. (Revision A.4). Gaussian, Inc., Carnegie, PA.

Gharibi E., Hbika A., Dupre B., and Gleitzer C. (1990) Electrical properties of pure and titanium-doped hematite single-crystals, in the basal-plane, at low oxygen-pressure. Eur. J. Sol. St. Inorg. Chem. 27, 647-658.

Goodenough J. B. (1972) Metallic oxides. Prog. Sol. St. Chem. 5, 145-399.

Graetzel M. (1989) Heterogeneous Photochemical Electron Transfer. CRC Press, Boca Raton.

Hay P. J. (1977) Gaussian basis sets for molecular calculations: The representation of $3 \mathrm{~d}$ orbitals in transition-metal atoms. J. Chem. Phys. 66, 4377.

Hendershot W. and Lavkulich L. (1983) Effect of sesquioxide coatings on surface charge of standard mineral and soil samples. Soil. Sci. Soc. Am. J. 47, 1252-1260.

Henrich V. E. and Cox P. A. (1994) The Surface Science of Metal Oxides. Cambridge University Press, Cambridge.

Hiesgen R., Meissner D., and Schmickler W. (2001) Tip effects in the scanning tunneling microscopy of semiconductor electrodes. Surf. Sci. 479, 183-190.

Hochella M. F. J., Eggleston C. M., Elings V. B., Parks G. A., Brown G. E. J., Wu C. M., and Kjoller K. (1989) Mineralogy in two dimensions: Scanning tunneling microscopy of semiconducting minerals with implications for geochemical reactivity. Am. Mineral. 74, $1233-1246$.

Hug S. J. (1997) In-situ Fourier transform infrared measurements of sulfate adsorption on hematite in aqueous solutions. $J$. Coll. Interf. Sci. 188, 415-422.

Jiang S., Frazier R., Yamaguchi E. S., Blanco M., Dasgupta S., Zhou Y., Cagin T., Tang Y., and Goddard W. A. I. (1997) The SAM model for wear inhibitor performance of dithiophosphates on iron oxide. $J$. Phys. Chem. B 101, 7702-7709.

Jones F., Rohl A. L., Farrow J. B., and van Bronswijk W. (2000) Molecular modeling of water adsorption on hematite. Phys. Chem. Chem. Phys. 2, 3209-3216. 
Junta-Rosso J. L. and Hochella M. F. J. (1996) The chemistry of hematite $\{001\}$ surfaces. Geochim. Cosmochim. Acta 60, 305-314.

Kallay N. and Matijevic E. (1985) Adsorption at solid/solution interfaces. 1. Interpretation of surface complexation of oxalic and citric acids with hematite. Langmuir 1, 195-201.

Klimkans A. and Larsson S. (1994) Reorganization energies in benzene, naphthalene, and anthracene. Chem. Phys. 189, 25-31.

Kurtz R. L. and Henrich V. E. (1987) Surface electronic structure and chemisorption on corundum transition-metal oxides: $\alpha-\mathrm{Fe}_{2} \mathrm{O}_{3}$. Phys. Rev. B 36, 3413-3421.

LaKind J. S. and Stone A. T. (1989) Reductive dissolution of goethite by phenolic reductants. Geochim. Cosmochim. Acta 53, 961-971.

Lee C. T., Yang W. T., and Parr R. G. (1988) Development of the Colle-Salvetti correlation-energy formula into a functional of the electron-density. Phys. Rev. B 37, 785-789.

Liu P., Kendelewicz T., Brown G. E. J., Nelson E. J., and Chambers S. A. (1998) Reaction of water vapor with $\alpha-\mathrm{Al}_{2} \mathrm{O}_{3}(0001)$ and $\alpha-\mathrm{Fe}_{2} \mathrm{O}_{3}(0001)$ surfaces: Synchrotron X-ray photoemission studies and thermodynamic calculations. Surf. Sci. 417, 53-65.

Logan J. and Newton M. D. (1983) Ab initio study of electronic coupling in the aqueous $\mathrm{Fe}^{2+}-\mathrm{Fe}^{3+}$ electron exchange process. J. Chem. Phys. 78(6), 4086-4091.

Lovley D. R. (1991) Dissimilatory Fe(III) and Mn(IV) reduction. Microbiol. Rev. 55, 259-287.

Lovley D. R. and Phillips E. J. P. (1988) Novel mode of microbial energy metabolism: Organic carbon oxidation coupled to dissimilatory reduction of iron or manganese. Appl. Environ. Microbiol. 54, $1472-1480$.

Lovley D. R. (1991) Dissimilatory Fe(III) and Mn(IV) reduction. Microbiol. Rev. 55, 259-287.

Marcus R. A. (1956) On the theory of oxidation-reduction reactions involving electron transfer. I. J. Chem. Phys. 24, 966-978.

Marcus R. A. (1965) On the theory of electron transfer reactions. VI Unified treatment for homogeneous and electrode reactions. J. Chem. Phys. 43, 679-701.

Marcus R. A. and Sutin N. (1985) Electron transfers in chemistry and biology. Biochim. Biophys. Acta 811, 265-322.

Marcus R. A. (1990) Reorganization free energy for electron transfers at liquid-liquid and dielectric semiconductor-liquid interfaces. $J$. Phys. Chem. 94(3), 1050-1055.

Monkhorst H. J. and Pack J. D. (1976) Special points for Brillouin zone integrations. Phys. Rev. B 13, 5188-5192.

Newton M. D. and Sutin N. (1984) Electron-transfer reactions in condensed phases. Ann. Rev. Phys. Chem. 35, 437-480.

Nordstrom D. K. and Southam G. (1997) Geomicrobiology of sulfide mineral oxidation. In Geomicrobiology: Interactions Between Microbes and Minerals (eds. J. F. Banfield and K. H. Nealson), Vol. 35 pp. 361-390. Mineralogical Society of America, Washington, D.C.

Payne M. C., Teter M. P., Allan D. C., Arias T. A., and Joannopoulos J. D. (1992) Iterative minimization techniques for ab initio totalenergy calculations: Molecular dynamics and conjugate gradients. Rev. Modern Phys. 64(4), 1045-1097.

Perdew J. P. and Wang Y. (1992) Accurate and simple analytic representation of the electron-gas correlation-energy. Phys Rev. B 45, $13244-13249$.

Ramachandran S., Tsai B.-L., Blanco M., Chen H., Tang Y., and Goddard W. A. I. (1996) Self-assembled monolayer mechanism for corrosion inhibition of iron by imidazolines. Langmuir 12, 64196428.

Rosso K. M. and Rustad J. R. (2000) Ab initio calculation of homogeneous outer sphere electron transfer rates: Application to $\mathrm{M}\left(\mathrm{OH}_{2}\right)_{(6)}{ }^{(3+/ 2+)}$ redox couples. J. Phys. Chem. A 104, 6718-6725.

Samson S. D. and Eggleston C. M. (1998) Active sites and the nonsteady-state dissolution of hematite. Environ. Sci. Technol. 32, 2871-2875.

Samson S. D., Stillings L. L., and Eggleston C. M. (2000) The depletion and regeneration of dissolution-active sites at the mineral-water interface: I. Fe, Al, and In sesquioxides. Geochim. Cosmochim. Acta 64, 3471-3484.

Scheidegger A., Borkovec M., and Sticher H. (1993) Coating of silica sand with goethite: Preparation and analytical identification. Geoderma 58, 43-65.
Schmickler W. (1993) Investigation of electrochemical electron transfer reactions with a scanning tunneling microscope: A theoretical study. Surf. Sci. 295, 43-56.

Schmickler W. and Tao N. (1997) Measuring the inverted region of an electron transfer reaction with a scanning tunneling microscope. Electrochim. Acta 42, 2809-2815.

Schmickler W. and Widrig C. (1992) The investigation of redox reactions with a scanning tunneling microscope. J. Electroanalyt. Chem. 336, 213-221.

Shaikhutdinov S. K. and Weiss W. (1999) Oxygen pressure dependence of the $\alpha-\mathrm{Fe}_{2} \mathrm{O}_{3}(0001)$ surface structure. Surf. Sci. Lett. 432, L627-L634.

Sherman D. M. (1987) Molecular orbital (SCF Xa-SW) theory of metal-metal charge transfer processes in minerals. 1. Application to $\mathrm{Fe}^{2+}$ to $\mathrm{Fe}^{3+}$ charge transfer and electron delocalization in mixed valence iron oxides and silicates. Phys. Chem. Minerals 14(4), 355-363.

Shuey R. T. (1975) Semiconducting Ore Minerals. Elsevier Scientific, Amsterdam.

Stumm W. (1992) Chemistry of the Solid Water Interface. John Wiley, New York.

Stumm W. and Morgan J. J. (1996) Aquatic Chemistry. John Wiley, New York.

Sulzberger B. and Hug S. (1994) Light-induced processes in the aquatic environment. In Chemistry of Aquatic Systems: Local and Global Perspectives (eds. G. Bidoglio and W. Stumm), pp. 183-212. ECSC, EEC, EAEC, Brussels.

Suter D., Banwart S., and Stumm W. (1991) Dissolution of hydrous iron(III) oxides by reductive mechanisms. Langmuir 7, 809-813.

Tao N. J. (1996) Probing potential-tuned resonant tunneling through redox molecules with scanning tunneling microscopy. Phys. Rev. Lett. 76, 4066-4069.

Tarrach G., Burgler D., Schaub T., Wiesendanger R., and Guntherodt H. J. (1993) Atomic surface structure of $\mathrm{Fe}_{3} \mathrm{O}_{4}(001)$ in different preparation stages studied by scanning tunneling microscopy. Surf. Sci. 285, 1-14.

Thevuthasan S., Kim Y. J., Yi S. I., Chambers S. A., Morais J., Denecke R., Fadley C. S., Lui P., Kendelewicz T., and Brown G. E. Jr. (1999) Surface structure of MBE-grown $\alpha-\mathrm{Fe}_{2} \mathrm{O}_{3}$ (0001) by intermediate-energy X-ray photoelectron diffraction. Surf. Sci. 425, $276-286$

Troullier N. and Martins J. L. (1991) Efficient pseudopotentials for plane-wave calculations. Phys. Rev. B 43, 1993-2006.

Wachters A. J. H. (1970) Gaussian basis set for molecular wavefunctions containing third-row atoms. J. Chem. Phys. 52, 1033.

Waite T. D. and Morel F. M. M. (1984) Photoreductive dissolution of colloidal iron oxide: Effect of citrate. J. Coll. Interf. Sci. 102, 121-137.

Wang X.-G., Weiss W., Shaikhutdinov S. K., Ritter M., Petersen M., Wagner F., Schlogl R., and Scheffler M. (1998) The hematite $(\alpha-$ $\mathrm{Fe}_{2} \mathrm{O}_{3}$ ) (0001) surface: Evidence for domains of distinct chemistry. Phys. Rev. Lett. 81, 1038-1041.

Wasserman E., Rustad J. R., Felmy A. R., Hay B. P., and Halley J. W. (1997) Ewald methods for polarizable surfaces with application to hydroxylation and hydrogen bonding on the (012) and (001) surfaces of $\alpha-\mathrm{Fe}_{2} \mathrm{O}_{3}$. Surf. Sci. 385, 217-239.

White J. A. and Bird D. M. (1994) Implementation of gradient-corrected exchange-correlation potentials in Car-Parrinello total energy calculations. Phys. Rev. B 50, 4954-4957.

\section{APPENDIX}

\section{PARAMETERIZATION OF THE RTM FOR STM IMAGE CALCULATION}

Schmickler and Widrig (1992) originally proposed a RTM, and assumed a planar, metallic substrate. Treating the substrate hematite as a metal, with a flat DOS, is strictly inaccurate because hematite is a wide band-gap semiconductor. In practice this simplification doesn't much affect the overall result unless we raise the substrate potential far above a resonance so that there must be a significant potential drop from the substrate conduction band to the redox center and so that there is significant direct substrate-to-tip electron transfer. 
To calculate images, we need values for the parameters in Eqns. 1 and 2 for each type of site for the terminations we wish to model (Table 2). Plane wave pseudopotential and cluster DFT calculations were used to predict $\mathrm{d}_{\mathrm{sr}}, \lambda\left(=\lambda_{\mathrm{is}}+\lambda_{\mathrm{os}}\right), \varepsilon_{\mathrm{r}}$ and contributed to the determination of $\beta$. The structures and related details of these calculations will be published elsewhere. Here we outline the critical components of the strategy and methods for the purposes of the RTM.

\section{Plane Wave Pseudopotential Calculations}

These calculations were performed to find the relaxed structures of the water-covered $\mathrm{Fe}$ - and $\mathrm{O}$-terminations. Periodic bulk and surface structures were optimized at the gradient-corrected DFT level using CASTEP (Payne et al., 1992). The generalized gradient-corrected local spin density approximation (GGS) was formulated using the Perdew and Wang (1992) parameterization of the exchange-correlation functional modified to work with plane wave calculations (White and Bird, 1994). We used the CASTEP parameterization of norm conserving pseudopotentials (Troullier and Martins, 1991). A cutoff energy of 760 $\mathrm{eV}$ was used; the calculations were determined to be suitably converged with respect to basis set size. Fourteen k-points were used for the optimization of the bulk, and two were used for slabs, according to the Monkhorst and Pack (1976) scheme. The atomic coordinates and cell parameters of bulk hematite were optimized simultaneously in the absence of symmetry restrictions (i.e., in the P1 space group). Charge neutral symmetric (001) slabs (approximately $10 \AA$ thick, containing a total of four Fe bilayers) were then cut from optimized bulk structures using a 10 - $\AA$-thick vacuum layer, and all atoms were allowed to relax using fixed lattice parameters from the bulk optimization. For the O-termination, under the assumption of a stoichiometric surface, surface charge neutrality dictates that the uppermost $\mathrm{O}$ plane is protonated. This is because the pristine O-termination has a formal residual charge of -3 per surface unit cell, leaving a surface with a permanent dipole moment perpendicular to the surface plane and causing instability with respect to reconstruction. Addition of a proton from the overlying water phase to each of the uppermost $\mathrm{O}$ atoms saturates this excess surface charge and gives an electrostatically stable surface. Neutral molecularly sorbed monolayers of water of the same density ( 2 waters per surface unit cell, one on the top surface and one on the bottom surface) were then added to both the Fe- and O-terminations, and all atoms were allowed to relax. After checking all reasonable adsorption sites in the surface unit cell, it was found that water molecules preferred to be located over the A-site on the Fe-termination and over the B-site on the $\mathrm{O}$-termination with the negative end of its dipole oriented towards the surface, consistent with the highest binding energy site for water being located over the uppermost cation. The target information from these calculations was 1) the optimized bond angles around the near-surface $\mathrm{Fe}$ sites without sorbed water for both terminations, 2) the preferred location of adsorbed water molecules in each surface unit cell, and 3) the interatomic distances between near-surface $\mathrm{Fe}$ atoms for watercovered surfaces for use as $d_{\text {sr }}$ parameters in the RTM. Optimized bond angles and preferred locations for adsorbed water were used to constrain the cluster calculations described below.

\section{Cluster Calculations}

Clusters that captured the coordination environments of the various near-surface $\mathrm{Fe}$ sites were excised from the slab-optimized vacuumterminated $\mathrm{Fe}$ - and O-terminations (surface protons on the O-termination were retained). The net formal charge initially remaining on each excised cluster was neutralized by systematic addition of protons to undersaturated oxygens, preserving optimized $\mathrm{Fe}-\mathrm{O}$ bond angles. Therefore, protons served both as surrogates for Fe-O bond charge density and to extend the accuracy of the description of the local site symmetry. Breathing optimizations of all bond lengths, keeping bond angles fixed, were then performed using Gaussian98 (Frisch et al, 1998) at the spin-unrestricted B3LYP level (Becke, 1993; Lee et al., 1988) using the Pople-type $6-311+\mathrm{G}$ basis set. The B3LYP method is a so-called hybrid DFT method that, like GGS, is based on gradient corrections to the electron density. The basis set consists of a WachtersHay 6-311G set (Wachters, 1970; Hay, 1977) with an added diffuse function ("+") (Clark et al., 1983). The spin multiplicity for each site cluster representation was fixed in accord with the expected magnetic structure. The breathing optimizations were performed to release any strain that might be present in the clusters due to the changeover from plane wave to localized orbital methods. Angles were kept fixed because the periodic treatment in the slab calculations more accurately predicts the surface structure. After the breathing optimizations, a water molecule was added appropriately to the A-site Fe cluster for the $\mathrm{Fe}$-termination and to the B-site cluster for the O-termination, based on the results from the slab optimizations. Then the Fe atom of interest in each cluster, and any associated sorbed water molecules, were allowed to fully optimize in all directions, while other atoms were held fixed. This step was then repeated for the case of an additional electron being present (i.e., the reduced case), mimicking local reduction of the site. The total electronic energy differences between the ferric and ferrous optimizations were used later to generate relative $\varepsilon_{\mathrm{r}}$ estimates for use in the RTM. The two energies also comprise two of the necessary four energies to compute $\lambda_{\text {is }}$ for reduction of the site (Klimkans and Larsson, 1994; Rosso and Rustad, 2000). The other two consist of the single point energies of the oxidized cluster in the reduced configuration, and the reduced cluster in the oxidized configuration. This 4-point $\lambda_{\text {is }}$ calculation is described in detail in Rosso and Rustad (2000). The cluster calculations thereby provided direct estimates of $\varepsilon_{\mathrm{r}}$ and $\lambda_{\mathrm{is}}$.

\section{Outer Sphere Reorganization Energy $\boldsymbol{\lambda}_{\mathrm{os}}$}

$\lambda_{\mathrm{os}}$, a term related in this case to the dielectric properties of hematite and of the overlying water at the surface, was estimated using continuum equations in Marcus (1990). For hematite, a static dielectric constant of 25 and an optical dielectric constant of 9 were used. The interface was designated as the plane going through the centers of the uppermost $\mathrm{O}$ plane for two reasons. First, this plane is the ideal registration point between the $\mathrm{Fe}$ - and $\mathrm{O}$-terminations. Second, the A-site density on the Fe-termination is only $1 / 3$ monolayer; the A-site therefore is more appropriately viewed as a protrusion into the overlying water phase. Thus, considering only electron transfers between the substrate $\mathrm{Fe}$ atoms and the redox center $\left(d_{s r}\right)$, only the electron transfer between the substrate and the A-site on the Fe-termination crosses the interface. Thus, for this step, we use Eqn. 16 (ET across an interface) in Marcus (1990) to calculate $\lambda_{\mathrm{os}}$. For all other substrateredox ET steps, we use the single phase equivalent, Eqn. 17 in Marcus (1990). The plane wave slab optimizations were used for the electron transfer distances and for site distances from the interface ( $\mathrm{R}$ and d's in Marcus, 1990). Fe-O bond lengths were used to approximate cavity radii (a's in Marcus, 1990). The resulting $\lambda_{\text {os }}$ values are added to the DFT-based $\lambda_{\text {is }}$ values from the cluster calculations to acquire the total reorganization energy $\lambda$.

\section{The $\boldsymbol{\beta}$ Parameter}

For ET on the Fe-termination from the hydrated A-site to either Fe atoms below in the substrate or above to the tip, $\beta$ can be taken as 1.2 $\AA^{-1}$ from Logan and Newton (1983). They used ab initio calculations to directly evaluate the electronic coupling between aquated $\mathrm{Fe}^{3+}-\mathrm{Fe}^{2+}$ octahedra through octahedral faces and through intervening water ligands in apex-to-apex orientations. Their face-to-face orientation is a close analog to the geometry of the hydrated A-site on the Fe-termination where electron transfer takes place along [001].

The preceding rationale for $\beta=1.2 \AA^{-1}$ is not as directly extendable to electron transfer between the intact $\mathrm{Fe}$ coordination environments deeper in the near-surface region, where intervening water is not ligating Fe. Therefore, we have also derived $\beta$ for these circumstances using a combination of our DFT cluster calculations, Marcus theory, macroscopic equations for electron mobility, and electrical conductivity measurements. Using a cluster that captures the fully coordinated $\mathrm{Fe}^{3+}$ site, we estimate $\lambda_{\text {is }}=0.274 \mathrm{eV}$ from the 4-point scheme. The $\lambda_{\text {os }}$ was $0.154 \mathrm{eV}$, as found using Eqn. 17 of Marcus (1990). Therefore, the total reorganization energy $(\lambda)$ for bulk hematite ET is $\lambda_{\text {is }}+\lambda_{\text {os }}=$ $0.428 \mathrm{eV}$. Presuming the splitting in the intersection region of the potential energy surfaces to be negligible for the moment, the Marcus equation (Marcus, 1956) may be used as a first estimate of the activation energy for ET $\left(\Delta G^{*}=\lambda / 4\right)$, giving $\Delta G^{*}=0.11 \mathrm{eV}$. More precisely, because the interaction of reactant orbitals couples the reactant and product states in the intersection region, $\Delta G^{*}$ tends to be reduced. Such an interaction is described by the off-diagonal matrix element $H_{A B}$ which equals the decrease in $\Delta G^{*} . H_{A B}$ is difficult to calculate from first principles, but in this case it can be deduced from 
our knowledge of $\lambda$ and previous electrical conductivity measurements For our case, we take $H_{A B}$ as equivalent to the transfer integral $\tau_{i j}^{\uparrow}$ in the language of solid-state physics. Based on an assumption of parabolic potential energy surfaces, $\Delta G^{*}$ can be related to $\lambda$ and $H_{A B}$ by (Sherman, 1987):

$$
\Delta G^{*}=\frac{2 \lambda-\left(\lambda^{2}-4 H_{A B}^{2}\right)^{0.5}}{4}-H_{A B}
$$

We may also relate measured drift mobilities $(\mu)$ of electrons to $\tau_{i j}^{\uparrow \uparrow}$ $\left(=H_{A B}\right)$ using (Goodenough, 1972):

$$
\mu=\left(e a^{2} / k T\right) \tau_{0}^{-1} \exp \left(-\Delta G^{*} / k T\right)
$$

where $e$ is the elementary charge, $a$ is the hopping distance $(\sim 3 \AA), k$ is the Boltzmann constant, and $T$ is temperature. The frequency $\tau_{0}^{-1}$ $\approx \tau_{i j}^{\Uparrow}$ where $\hbar$ is Planck's constant. Bosman and van Daal (1970) determined that $\mu=0.1 \mathrm{~cm}^{2} \mathrm{~V}^{-1} \mathrm{~s}^{-1}$ within basal planes of hematite. Using this $\mu, \lambda=0.428 \mathrm{eV}$, and taking $H_{A B}=\tau_{i j}^{\Uparrow}$, we solve Eqns. A1 and $\mathrm{A} 2$ for equivalence in $\Delta G^{*}$ and $H_{A B}$, giving $\Delta G^{*}=0.074 \mathrm{eV}$ and $H_{A B}=0.034 \mathrm{eV}$ for electron hopping along basal planes in hematite. $\Delta G^{*}$ compares very well with the $<0.1 \mathrm{eV}$ estimate in Goodenough (1972) and $0.08 \mathrm{eV}$ based on the conductivity measurements of Gharibi et al. (1990). Also, $H_{A B}$ agrees reasonably well with the $0.016 \mathrm{eV}$ estimate by Gharibi et al. (1990).

We may also use the functional form of Eqn. A2 to determine the distance dependence and thus the parameter $\beta$ for ET within hematite basal planes. The distance dependence is typically exponential according to (Newton and Sutin, 1984):

$$
H_{A B}=H_{A B}^{0} \exp \left[-\beta\left(r-r_{0}\right) / 2\right]
$$

where $r$ is the distance, $r_{O}$ and $H_{A B}^{0}$ are the distance and electronic coupling, respectively, where ET is optimal, or fixed as in this case. Using $a=r_{0}=3 \AA, H_{A B}^{0}=\tau_{i j}^{\uparrow}$, and $\mu=0.1 \mathrm{~cm}^{2} \mathrm{~V}^{-1} \mathrm{~s}^{-1}$, a least-squares fit of Eqn. A3 to the distance dependence described by Eqn. A2 gives $\beta=1.013 \AA^{-1}$ and an $\mathrm{R}^{2}=0.995$. This is the estimate of $\beta$ we use for $\mathrm{Fe}^{3+}$ sites in the bulk-like environments near the basal surface (i.e., $\beta_{s r}$ and $\beta_{r t}$ for $\mathrm{B}$ and $\mathrm{C}$ sites in the Fe-termination and for the $\mathrm{A}, \mathrm{B}$, and $\mathrm{C}$ sites in the O-termination).

The antiferromagnetic structure of hematite along [001] imposes restrictions on electron transfer between certain Fe atoms (Goodenough, 1972). The high-spin $\mathrm{d}^{5}$ molecular orbitals of each $\mathrm{Fe}^{3+}$ site can only accept electrons of opposite spin. There are two ways in which we have dealt with spin restrictions on ET. One way is to ignore spin restrictions, and treat all nearest neighbors for a given resonator as potential electron "sources" (Table 2). For example, an "A" site could receive electrons from any of three nearest-neighbor "B" sites. We also treat the surface structure as antiferromagnetic. Bulk hematite is antiferromagnetic, with iron between oxygen layers having the same spin but opposite spin across oxygen layers. That this arrangement should persist at the basal surface is supported by our plane wave pseudopotential slab calculations, as well as by Becker et al. (1996). An A site could then only receive electrons from the $\mathrm{Fe}$ atom directly below it (Fig. 1a); ET from B- and C-type sites to A sites would be spinforbidden. 